\title{
Discrete element modelling of railway ballast performance considering particle shape and rolling resistance
}

\author{
Yunlong Guo $^{1} \cdot$ Chunfa Zhao $^{2} \cdot$ Valeri Markine $^{1} \cdot$ Can Shi $^{2} \cdot$ Guoqing Jing $^{3} \cdot$ \\ Wanming Zhai ${ }^{2}$
}

Received: 11 May 2020/Revised: 14 July 2020/Accepted: 20 July 2020/Published online: 27 August 2020

(C) The Author(s) 2020

\begin{abstract}
To simulate ballast performance accurately and efficiently, the input in discrete element models should be carefully selected, including the contact model and applied particle shape. To study the effects of the contact model and applied particle shape on the ballast performance (shear strength and deformation), the direct shear test (DST) model and the large-scale process simulation test (LPST) model were developed on the basis of two types of contact models, namely the rolling resistance linear (RRL) model and the linear contact (LC) model. Particle shapes are differentiated by clumps. A clump is a sphere assembly for one ballast particle. The results show that compared with the typical LC model, the RRL method is more efficient and realistic to predict shear strength results of ballast
\end{abstract}

Can Shi

shican@my.swjtu.edu.cn

Yunlong Guo

yunlong.guo@tudelft.nl

Chunfa Zhao

cfzhao@swjtu.edu.cn

Valeri Markine

v.l.markine@tudelft.nl

Guoqing Jing

gqjing@bjtu.edu.cn

Wanming Zhai

wmzhai@swjtu.edu.cn

1 Faculty of Civil Engineering and Geosciences, Delft University of Technology, 2628CN Delft, The Netherlands

2 Train and Track Research Institute, State Key Laboratory of Traction Power, Southwest Jiaotong University, Chengdu 610031, China

3 School of Civil Engineering, Beijing Jiaotong University, Beijing 100044, China assemblies in DSTs. In addition, the RRL contact model can also provide accurate vertical and lateral ballast deformation under the cyclic loading in LPSTs.

Keywords Discrete element method B Ballast performance - Boundary condition $\cdot$ Rolling resistance $\cdot$ Direct shear test - Lateral displacement

\section{Introduction}

Railways play a significant role in the transportation system worldwide and work in many sectors (urban rail, highspeed railway, heavy haul, intercity and metro) [1, 2]. Ballasted tracks, as the most widely used track type, consist of rails, sleepers and the ballast layer [3, 4]. It possesses the advantages such as low construction cost, simple design and construction, and easy maintenance [5].

The ballast layer, a crucial component of ballasted track, provides resistances to sleepers, transmits and distributes the loads or impacts from sleepers to the subgrade, as well as allows rapid drainage [6]. Generally, it is composed of blasted (quarried) rock aggregate, which is required to meet certain characteristics such as narrow-graded $(20-60 \mathrm{~mm})$ and irregular particle shape, specific surface roughness, density, hardness, resistance to attrition and weathering [7]. Even though various railway ballast standards in terms of particle size distribution or particle shape have already been formulated [7-9], their influences on ballast performance (resilience, shearing strength, and settlement) have not been sufficiently studied $[10,11]$. 
Laboratory or field tests are of limited use in studying the ballast performance, because the test conditions cannot be kept the same and many characteristics (e.g. ballast density and sleeper type) cannot be controlled [12]. Additionally, due to the discrete nature of ballast, it is not accurate or realistic to use the finite element method, which simulates the ballast layer as continuous layer [13]. The ballast performance keeps changing due to the ballast degradation (abrasion and breakage) [12, 14-16]. In addition, the sliding and rolling of individual ballast particles also influence the performance of the ballast layer [17].

The discrete element method (DEM) can overcome the limitations of laboratory or field tests and the finite element models [18, 19]. As a powerful tool, it can (1) obtain all responses of the particles during simulations (e.g. velocity, displacement, acceleration, and contact forces), (2) account for the properties of granular materials (density, size, and shape) [20], and (3) include the effects of breakage or abrasion [17, 21-25].

Earlier studies have shown the feasibility of the DEM in evaluating the ballast performance [26-32]. However, there still exist some aspects for improvement.

On the one hand, the computational cost is the most considerable limitation in developing DEM models that may have millions of spheres (e.g. full-scale track model) [21]. Larger number of particles means the increase in the total number of particle contacts, which results in great computational cost. This problem becomes more severe when non-spherical particles are present in the DEM models. The usage of the non-spherical particles can provide more realistic load-deformation response [18, 33]. A non-spherical particle is generally made by a sphere assembly, named clump or cluster in the particle flow code (PFC, commercial DEM software) [27, 34]. Using the nonspherical particles (sphere assembly) increases the spheres and the number of contacts (contact points between the particles). The contacts are updated with every cycle according to the force-displacement law, which finally increases the computation time considerably.

In most cases, the contact method used in the earlier models was elementary linear model (spring-damping model). By using the RRL, simple spheres can also be possible to attain similar ballast performance, which can save a large amount of computational time. For example, it was demonstrated that the linear rolling resistance contact model (using spheres as ballast particles) can obtain the same ballast lateral resistance results as those from field tests [35].

On the other hand, even if the sleeper-ballast model uses the simple spherical or less-spherical particles, it has to be developed in a large-scale manner (e.g. three-sleeper track model) due to the scale effect and the boundary condition. The scale effect means that the sample dimensions should be $4-6$ times larger than the ballast particle (in laboratory tests), to ensure that the results are stable and unaffected [19]. The boundary condition means that when a DEM model represents only a part of the whole system (e.g. halfsleeper track model for the whole ballasted track), the model boundary normally provides different reactions (displacements, forces). For example, when building the half-sleeper track model by DEM, the boundary of the ballast layer is mostly restricted (no displacements) [36]. This will lead to false boundary-ballast reaction, since the boundary imposes larger forces to the contact ballast particles than in reality. When applying the dynamic loads, such boundary condition will result false results due to waves reflection effect.

To solve the issue of the boundary condition, the largescale process simulation test (LPST) model as described in [18] was developed, in contrast to small-scale track model (e.g. ballast box test model) [37]. It has five movable walls at one side to provide consistent pressure stress during the cyclic loading, and in this way the boundary condition is included by moving the lateral walls and providing the lateral deformation.

Therefore, to develop an efficient and accurate method for DEM simulation, this work explores the effects of the rolling resistance linear (RRL) model on the ballast performance of the direct shear test (DST) model and LPST model. The shear strength and settlement of the RRL model is compared with those of the LC model. Specifically, the contact model of the spheres is the RRL, whereas the LC model is used for the non-spherical particles.

\section{Methodology}

The DST model and LPST model are developed with the commercial DEM software called Particle Flow Code in 3D (PFC3D). The numerical results derived from these models are compared with those from Ref. [18]. The adoption of two models can fully describe ballast performance such as shear strength, resilience, settlement/permanent deformation. Of these indicators, the shear strength is most widely used and is measured generally by the DSTs $[12,28,38]$. The settlement/permanent deformation is another key characteristic concerning the performance of ballast assemblies (especially in the field), and is measured by the cutting-edge LPSTs [18]. More importantly, this test model is applicable to the lateral deformation of the ballast assemblies.

\subsection{DST}

Figure 1 presents the setup of the DST and the corresponding DEM models. The contact model parameters in 

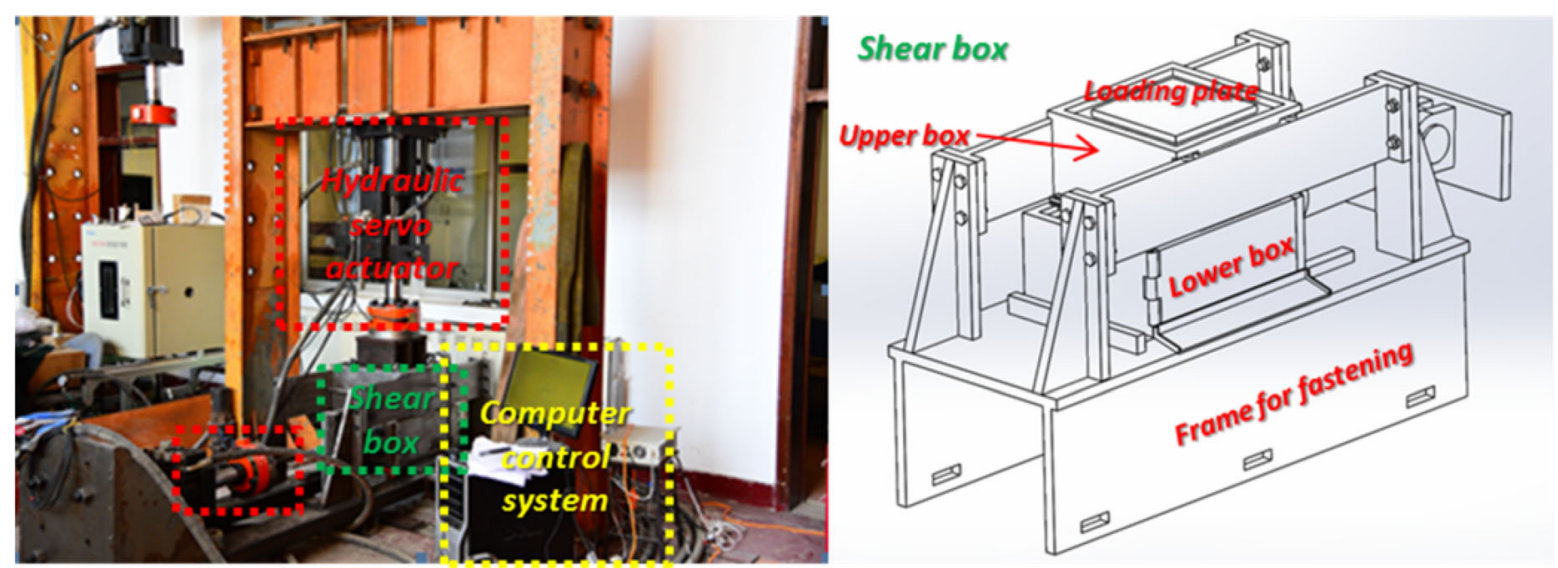

(a) Direct shear test (experimental test)

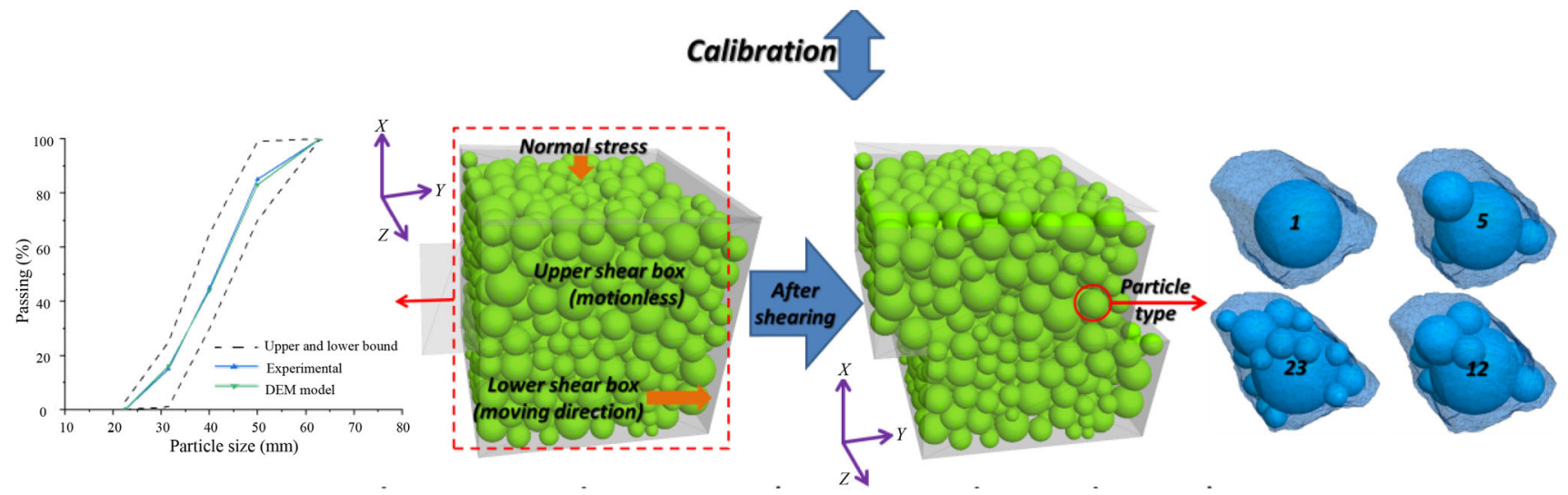

(b) Direct shear test (numerical simulation)

Fig. 1 Schematic diagram of the applied methodology

the DST model are calibrated using the DST results. Afterwards, we compare the results obtained from two different contact models, i.e. the RRL model and the LC model.

\subsubsection{Experimental}

In the DSTs, the ballast material is the commonly used aggregate of basalt rock produced in Quarry Pulandian, Dalian, China. The ballast particles have a uniformed shape, sufficient strength, and particle size distribution that follow the British standard [7]. The ballast density is $2530 \mathrm{~kg} / \mathrm{m}^{3}$.

The DST rig consists of three main parts: a steel square box, two hydraulic servo actuators and a computer control system (see Fig. 1a). The steel square consists of an upper steel square box (inner size: $400 \mathrm{~mm} \times 400 \mathrm{~mm} \times 200 \mathrm{~mm}$ ), a lower steel square box (inner size: $400 \mathrm{~mm} \times 400 \mathrm{~mm} \times 200 \mathrm{~mm}$ ) and a steel loading plate (size: $400 \mathrm{~mm} \times 400 \mathrm{~mm} \times 20$ $\mathrm{mm})$. There is a gap of $10 \mathrm{~mm}$ between the upper and lower boxes.
The vertical and lateral hydraulic servo actuators can create the maximum loading of $30 \mathrm{t}$ and $10 \mathrm{t}$, respectively (Fig. 1a). The vertical actuator can apply the normal force on the steel plate placed on the top of the upper box. This is utilised to provide a constant normal stress in ballast samples. The lateral actuator is used to shift the lower box with a constant speed.

The computer control system is utilised to measure vertical and lateral displacements through the linear variable differential transformers (LVDT). It also controls the application of the force or speed of the two hydraulic actuators and records the applied stress.

The ballast particles are placed in the shear box and experience three steps. After placing ballast particles each time, a vibratory compactor is used for compacting the layer. After the third time of compaction, the steel plate (weight of $25.64 \mathrm{~kg}$ ) is placed on the top of the ballast sample. Then, the direct shear tests are performed at a shearing speed of $2 \mathrm{~mm} / \mathrm{min}$ under three different normal stresses of 24,54 and $104 \mathrm{kPa}$. The final horizontal 
displacement of the lower DST box is $80 \mathrm{~mm}$ (20\% shear strain), which is adequate to obtain the peak shear stress.

\subsubsection{DST model description}

The DST model (Fig. 1b) is utilised to measure the shear strength of the two contact models and four kinds of particle shapes. The porosity of the sample is 0.4 , and the particle size distribution (PSD) is based on the above experimental tests. Note that the PSD of all the models remains the same. The model configuration is set as the experimental test configuration (Fig. 1a), including the box size and the applied normal stresses.

The basic contact mode of DEM is a kind of spheresphere contact interactions. Even though in some models the non-spherical particles (clumps) are used, the interaction in the contact areas is still based on the sphere-sphere contact model [39]. However, if the non-spherical particles are present, the number of contact points increases and particle interlocking occurs, finally restraining the particle rotation. On the other hand, if there are simple-shape particles (spheres) with certain rolling friction, it is also possible to result the same effect as the non-spherical particles [35]. Therefore, the rolling friction [39] is used in the DST model.

\subsubsection{Contact model and particle shape}

In order to determine whether the simple-shape (sphere) particles with the rolling friction can provide the same performance of the model as the complex-shape (clump) particles, two types of contact model are utilised in the model, namely, the LC model and the RRL model. The models with the spheres use the RRL model, while the models with the clumps use the LC model.

The RRL model has one more parameter (rolling friction) than the LC model. In other words, the only difference between the two contact models is the rolling friction. The rolling friction will resist the particle rolling when a force is acting on it. To be more specific, the rolling friction decides the maximum value that equals to the product of the rolling friction with the corresponding normal force. The restriction is defined as rolling stiffness that is assumed as the clockwork spring (Fig. 2), and it increases with the relative rotation.

The four types of the particle shape used in the models are a sphere, a 5-sphere clump, a 12-sphere clump and a 23 -sphere clump. Note that one model corresponds to only one type of particle shape. The clump particles are created with the identical template that was obtained by scanning the real ballast particle [40].

In addition, the normal stiffness and shear stiffness (the springs in Fig. 2) are another two parameters in the two contact models that considerably influence the calculation time. Figure 2 describes the LC model.

The calculation time is decided by the timestep calculated based on the two types of stiffness. Specifically, a higher stiffness leads to a smaller timestep, causing more calculation time. The timestep is the smallest time period in simulation, in which the force-displacement law is applied to every updated contact. In other words, a particle moves at a speed in one timestep, and after the time is reached, the forces and displacements are updated. The specific introduction of the timestep can be found in [39]. For this, several values of these two parameters (shear and normal stiffnesses) are selected, and the results are compared for both efficient and accurate simulation.

The properties of the DST model and contact model parameters are listed in Table 1, where four DST models respectively use four types of particle shapes, i.e. the sphere, 5-sphere clump, 12-sphere clump and 23-sphere clump. For the DST model using spheres, the RRL model is utilised, and the particle-particle rolling friction coefficient and the values of the two stiffness (normal and shear) are calibrated. For the DST models using non-spherical particles, the LC model is used and its results are compared with that of the DST model using spheres.

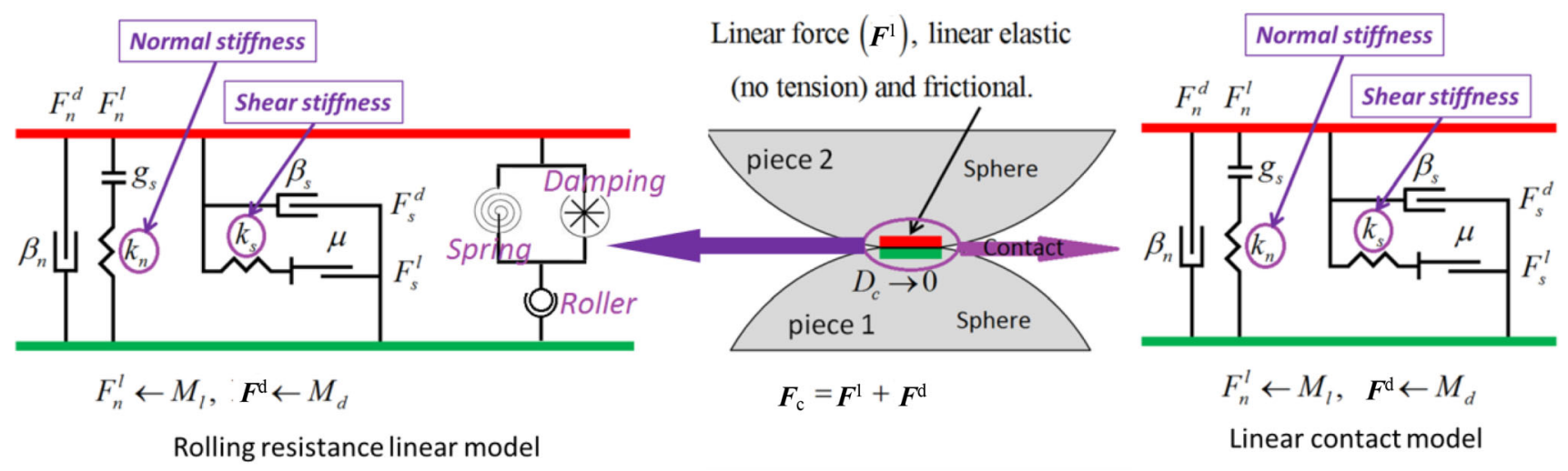

Fig. 2 Diagram of the normal stiffness and shear stiffness (modified after [39]) 
Table 1 Properties of DST model and contact model parameters

Value

With sphere

Contact model type

Rolling resistance linear contact model

Particle type

Sphere

Density $\left(\mathrm{kg} / \mathrm{m}^{3}\right)$

2530.0

Particle-particle friction coefficient

0.5

Particle-particle rolling friction coefficient

$0.1,0.2,0.3,0.4,0.5$ and 0.6

Normal stiffness $(\mathrm{N} / \mathrm{m})$

$4 \times 10^{5}, 1 \times 10^{6}, 1 \times 10^{7}$ and $1 \times 10^{8}$

Shear stiffness $(\mathrm{N} / \mathrm{m})$

$4 \times 10^{5}, 1 \times 10^{6}, 1 \times 10^{7}$ and $1 \times 10^{8}$

Gravity $\left(\mathrm{m} / \mathrm{s}^{2}\right)$

9.81

Damping

0.9

With clump

Contact model type

Linear contact model

Particle type

Density $\left(\mathrm{kg} / \mathrm{m}^{3}\right)$

5-sphere clump/12-sphere clump/23-sphere clump 2530.0

Particle-particle friction coefficient $\quad 0.5$

Normal stiffness $(\mathrm{N} / \mathrm{m}) \quad 4 \times 10^{5}, 1 \times 10^{6}, 1 \times 10^{7}$ and $1 \times 10^{8}$

Shear stiffness $(\mathrm{N} / \mathrm{m}) \quad 4 \times 10^{5}, 1 \times 10^{6}, 1 \times 10^{7}$ and $1 \times 10^{8}$

Gravity $\left(\mathrm{m} / \mathrm{s}^{2}\right) \quad 9.81$

Damping $\quad 0.9$

Table 2 Model properties and parameters of large-scale process simulation test

\section{Value}

With sphere

Contact model type

Particle type

Density $\left(\mathrm{kg} / \mathrm{m}^{3}\right)$

Rolling resistance linear contact model

Particle-particle friction coefficient

2530.0

Particle-particle rolling friction coefficient

0.5

Normal stiffness $(\mathrm{N} / \mathrm{m})$

0.3

Shear stiffness $(\mathrm{N} / \mathrm{m})$

Gravity $\left(\mathrm{m} / \mathrm{s}^{2}\right)$

$1 \times 10^{5}, 2 \times 10^{5}, 4 \times 10^{5}$ and $1 \times 10^{6}$

Damping

$1 \times 10^{5}, 2 \times 10^{5}, 4 \times 10^{5}$ and $1 \times 10^{6}$

9.81

With clump

Contact model type

Particle type

Density $\left(\mathrm{kg} / \mathrm{m}^{3}\right)$

0.9

Particle-particle friction coefficient

Rolling resistance linear contact model

5-sphere clump/12-sphere clump/23-sphere clump 2530.0

Particle-particle rolling friction coefficient

0.5

Normal stiffness $(\mathrm{N} / \mathrm{m})$

0.0

Shear stiffness $(\mathrm{N} / \mathrm{m})$

$4 \times 10^{5}, 1 \times 10^{6}, 1 \times 10^{7}$ and $1 \times 10^{8}$

Gravity $\left(\mathrm{m} / \mathrm{s}^{2}\right)$

$4 \times 10^{5}, 1 \times 10^{6}, 1 \times 10^{7}$ and $1 \times 10^{8}$

9.81

Damping

0.9

The damping applied in the model is local damping (not damping at particle contacts), and the damping value is set according to Ref. [41]. Though there is no consensus in a universal damping value, it has little influence on comparison results. Moreover, it has been proved that different damping values have little influence on the shear strength results when the shear speed is very slow. High 

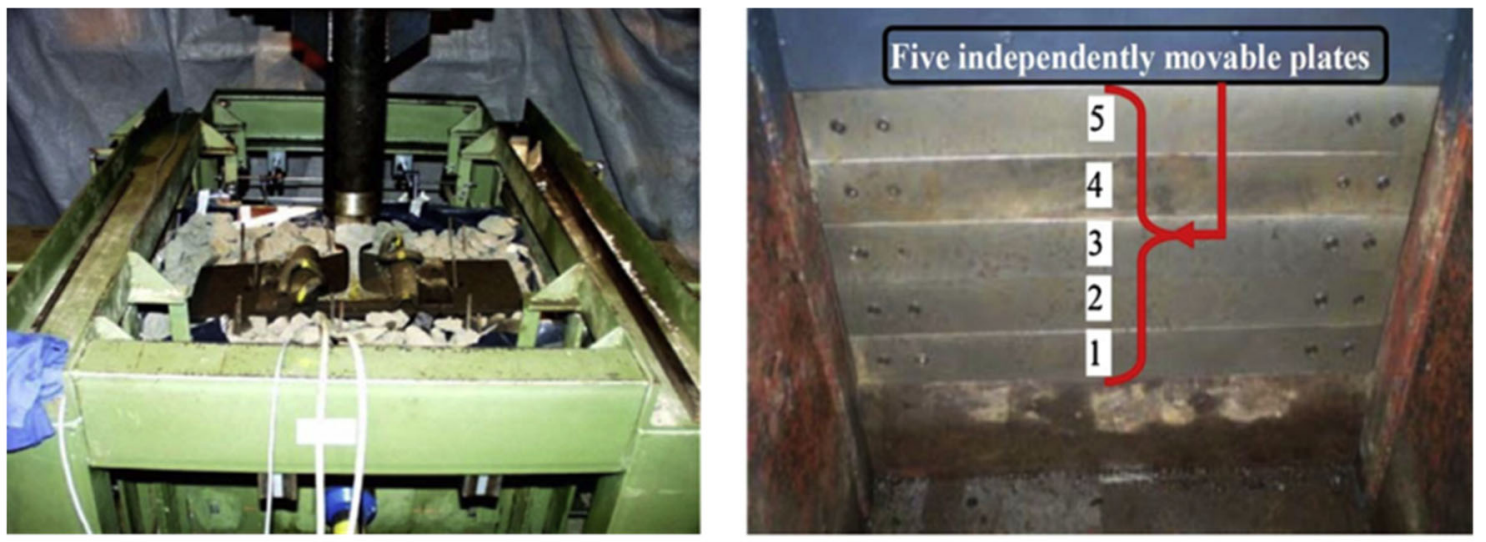

(a) Large-scale process simulation test

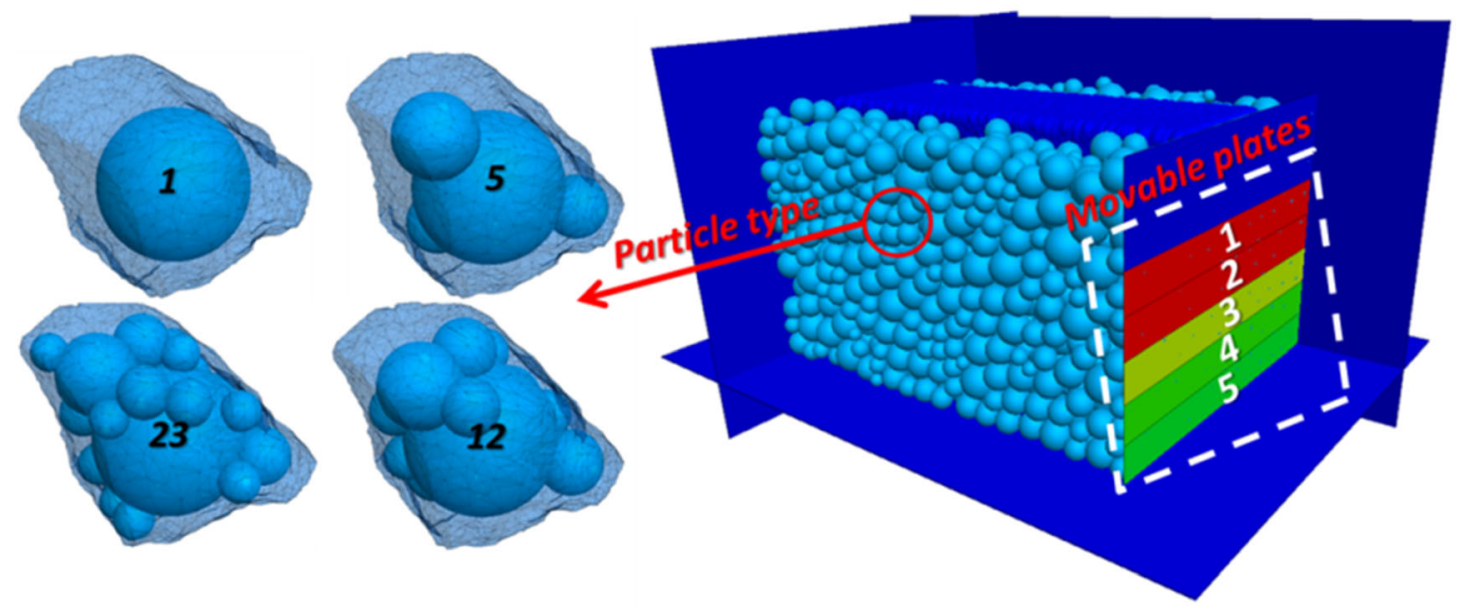

(b) Large-scale process simulation test model

Fig. 3 Large-scale process simulation test and DEM model (Fig.3a reproduced from [18])

damping value tends to accelerate the formation of equilibrium state.

\subsection{Model description of large-scale process simulation test}

The development of the LPST model refers to the LPST apparatus. As shown in Fig. 3a, the LPST apparatus was designed by Indraratna to develop physical simulation of "in situ" railway track. It can contain specimens that are $800 \mathrm{~mm}$ long, $600 \mathrm{~mm}$ wide, and $600 \mathrm{~mm}$ high [42]. Most importantly, one side of the apparatus is made by five movable plates, which can provide consistent principal stresses in the cyclic loading. More explanations on the LPST apparatus can be found in Ref. [3].

The LPST model shown in Fig. $3 b$ includes sleeper, ballast layer and test box. The dimension of the specimen is $800 \mathrm{~mm} \times 600 \mathrm{~mm} \times 475 \mathrm{~mm}$, with the ballast thickness (under the sleeper) of $325 \mathrm{~mm}$. The sleeper is constituted by the overlapped spheres (clump), and the ballast particles are simulated with spheres or clumps (same as DST model).

For the model with the spheres, the sample porosity is 0.354 , which is larger than the one (0.338) in Ref. [18], whereas the models with three types of clumps have the same porosity (0.338). Even though the porosity is different, the results have shown that their performances can still be the same.

The model properties and parameters are listed in Table 2, including density, friction, stiffness, rolling friction, etc. The movable plates are simulated by walls that keep moving slightly to provide consistent principal stress (10 kPa). The maximum moving speed of the plates is set as $10 \mathrm{~mm} / \mathrm{s}$.

Four developed LPST models use four different types of particle shapes, i.e. the sphere, 5-sphere clump, 12-sphere clump and 23-sphere clump. For the model with spheres, the RRL model is utilised and the values of 


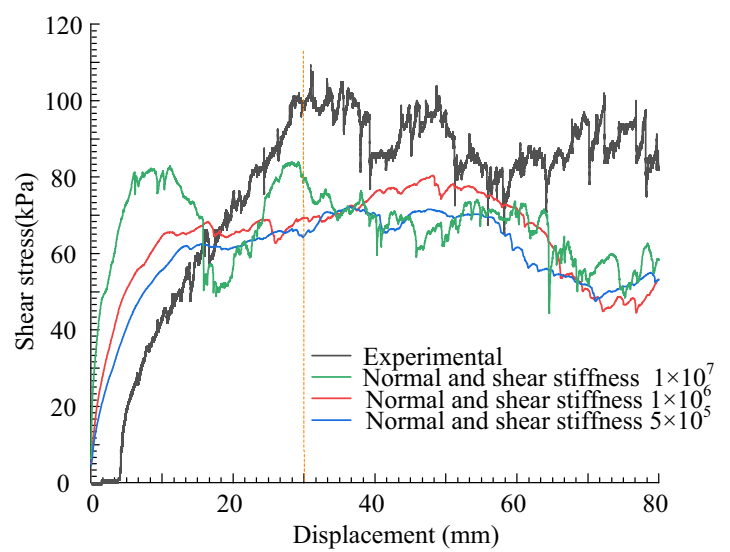

(a) Rolling friction coefficient 0.1

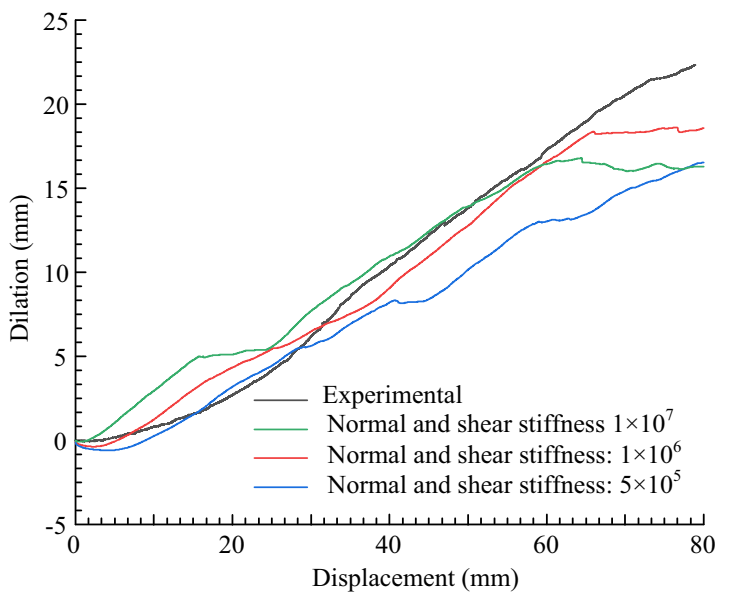

(c) Rolling friction coefficient 0.1

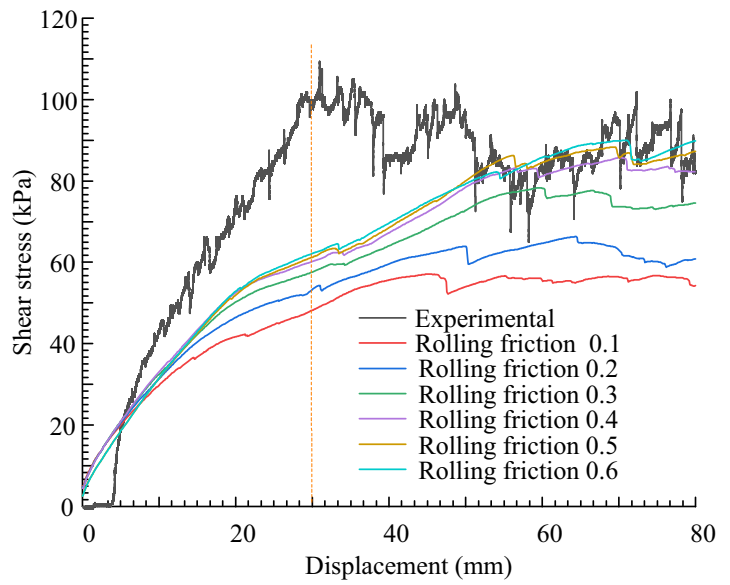

(e) Normal and shear stiffness $1 \times 10^{5}$

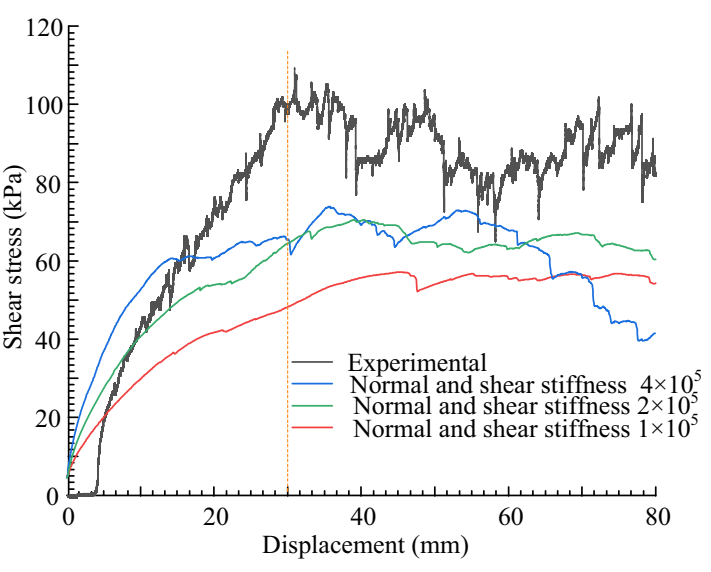

(b) Rolling friction coefficient 0.1

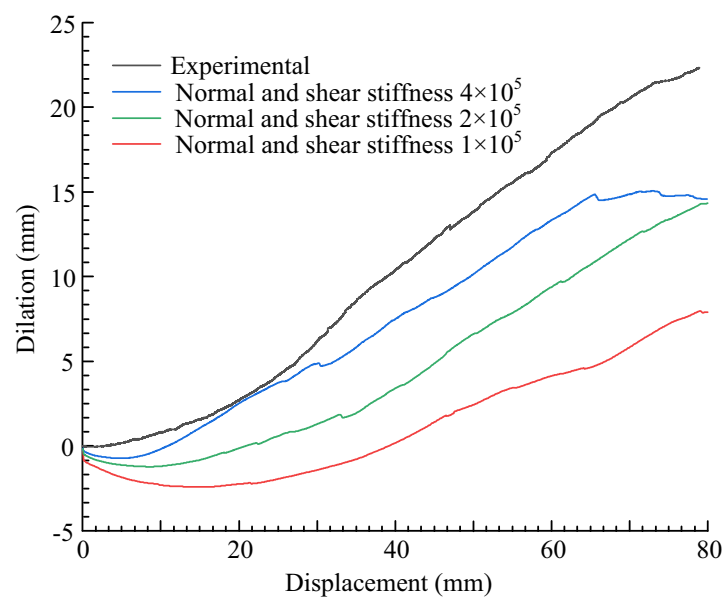

(d) Rolling friction coefficient 0.1

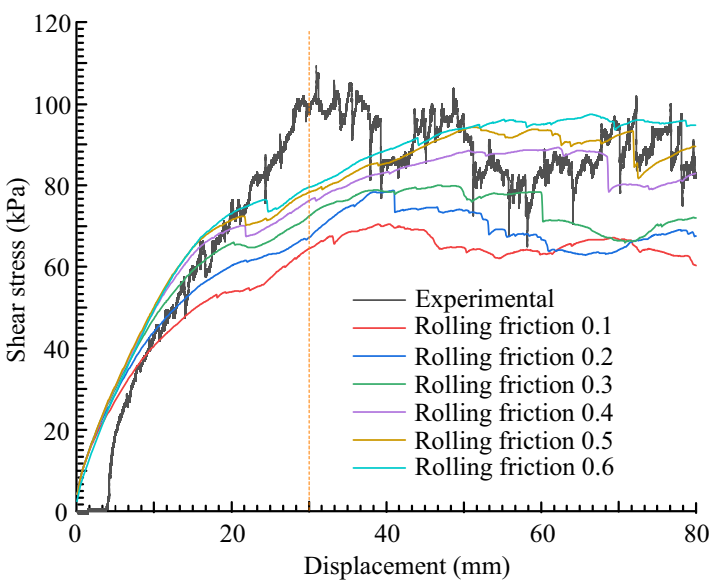

(f) Normal and shear stiffness $2 \times 10^{5}$

Fig. 4 Shear stress and deformation results of the DST simulation with sphere under the normal stress $24 \mathrm{kPa}$ 


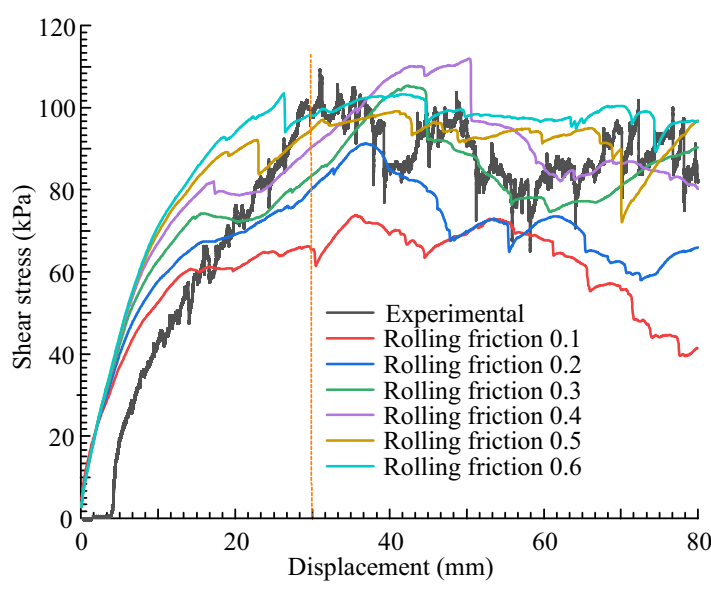

(g) Normal and shear stiffness $4 \times 10^{5}$

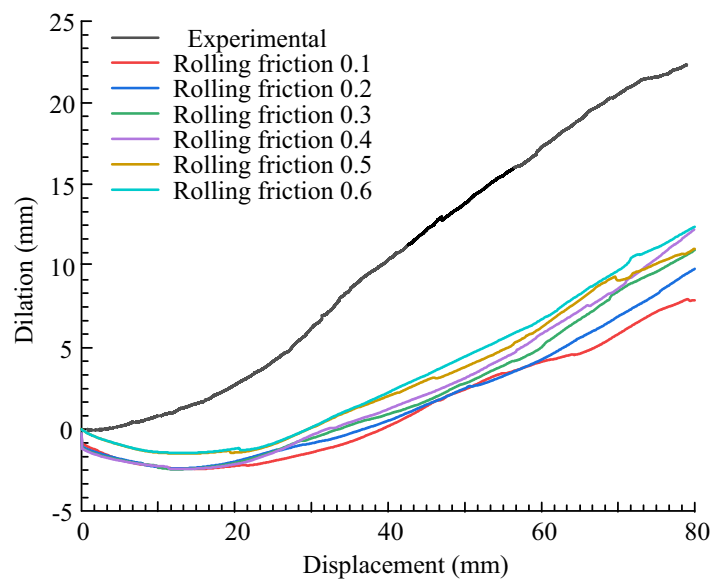

(i) Normal and shear stiffness $1 \times 10^{5}$

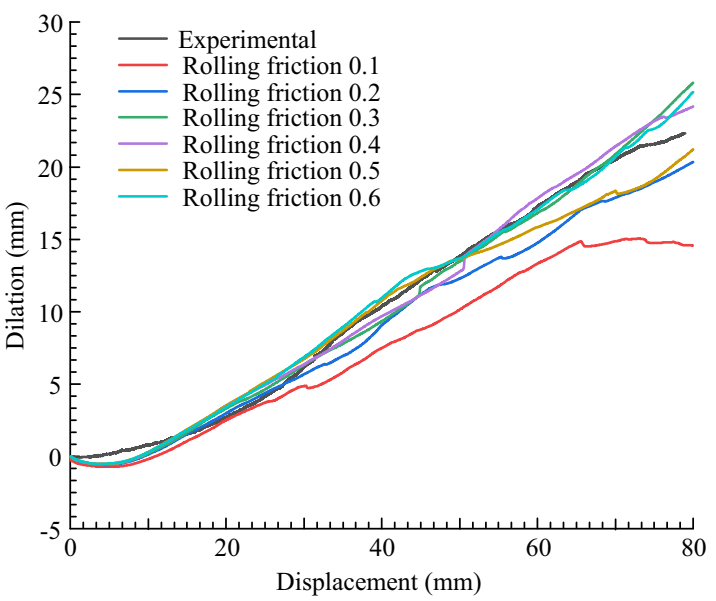

(k) Normal and shear stiffness $4 \times 10^{5}$

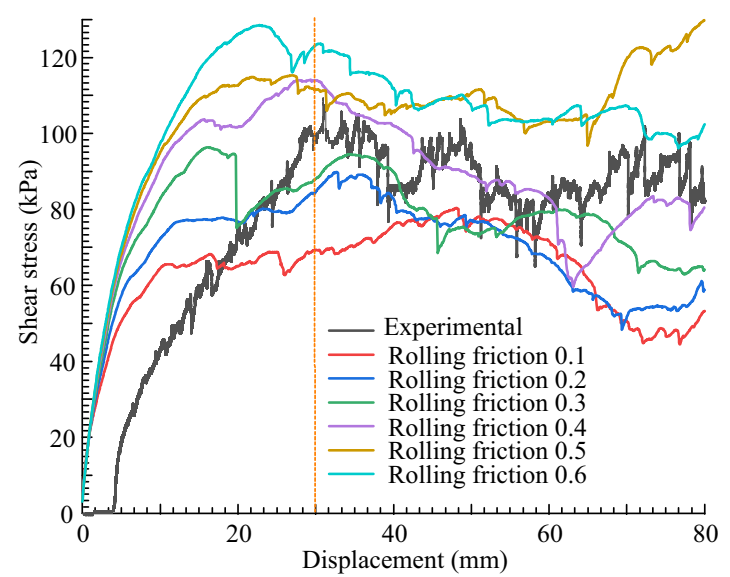

(h) Normal and shear stiffness $1 \times 10^{6}$

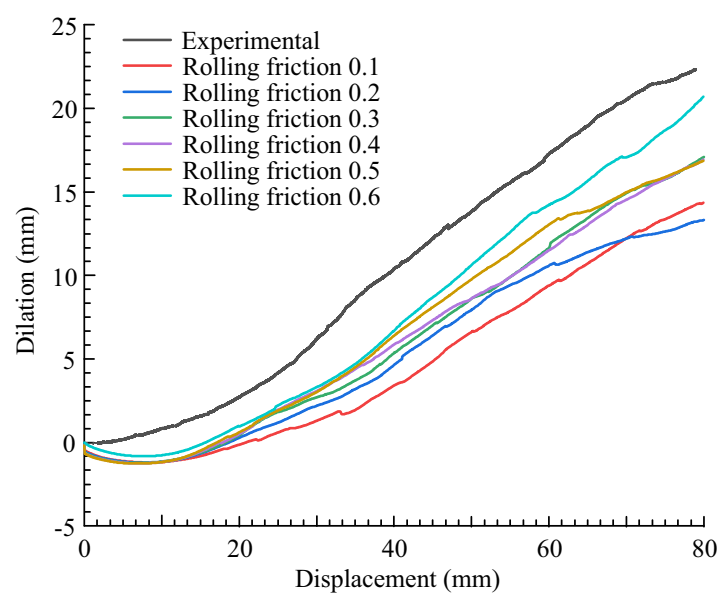

(j) Normal and shear stiffness $2 \times 10^{5}$

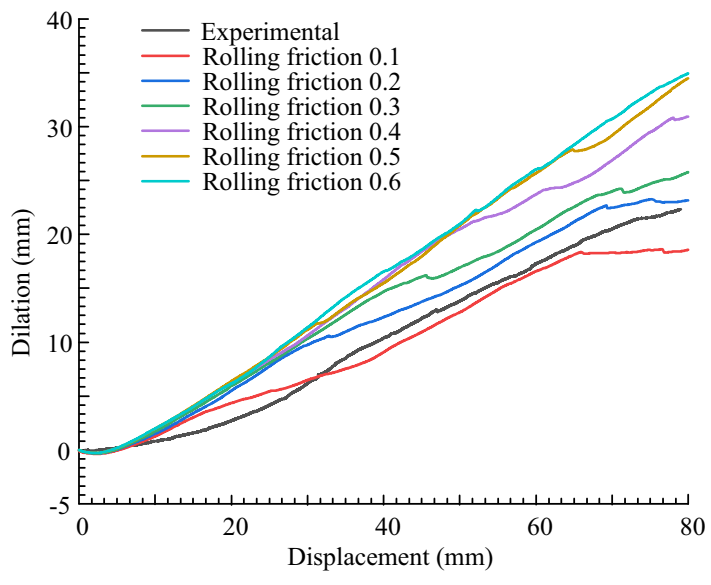

(l) Normal and shear stiffness $1 \times 10^{6}$

Fig. 4 continued 


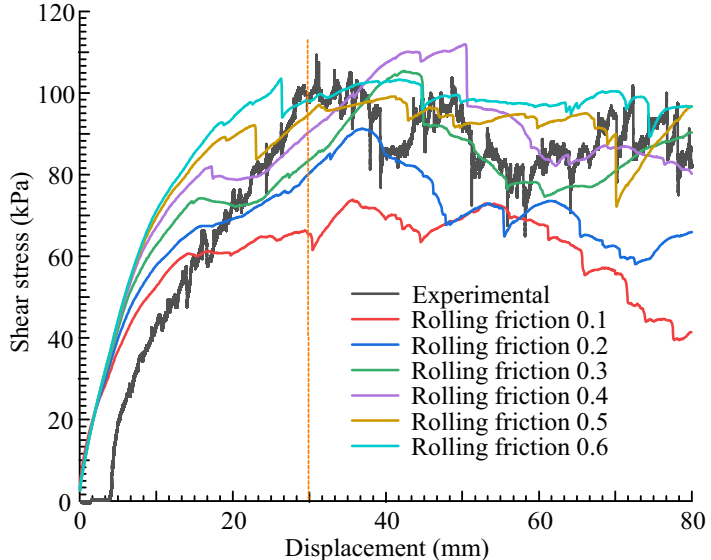

(a) Normal stress $24 \mathrm{kPa}$

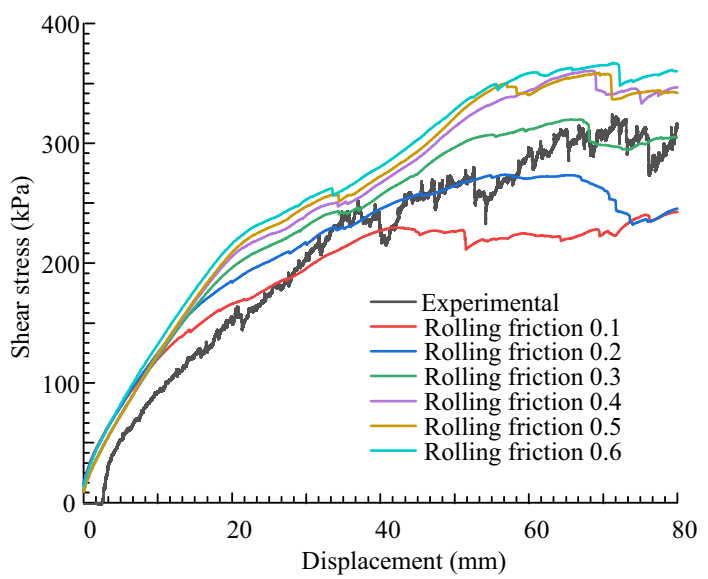

(c) Normal stress $104 \mathrm{kPa}$

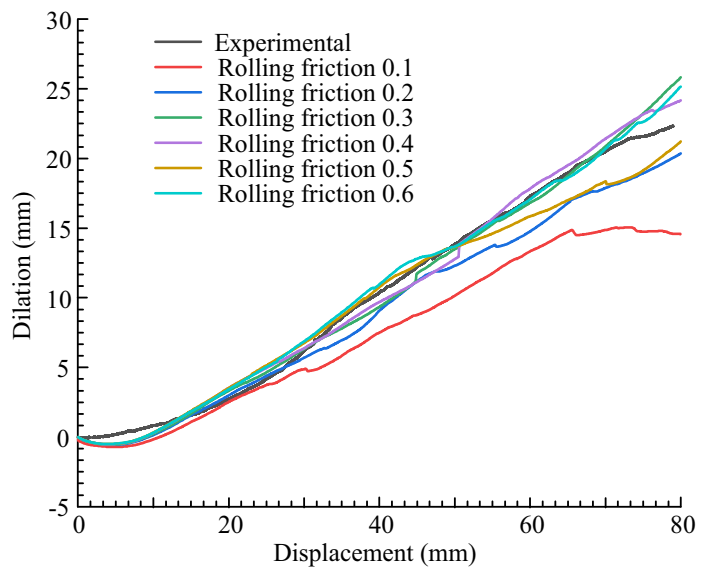

(e) Normal stress $24 \mathrm{kPa}$

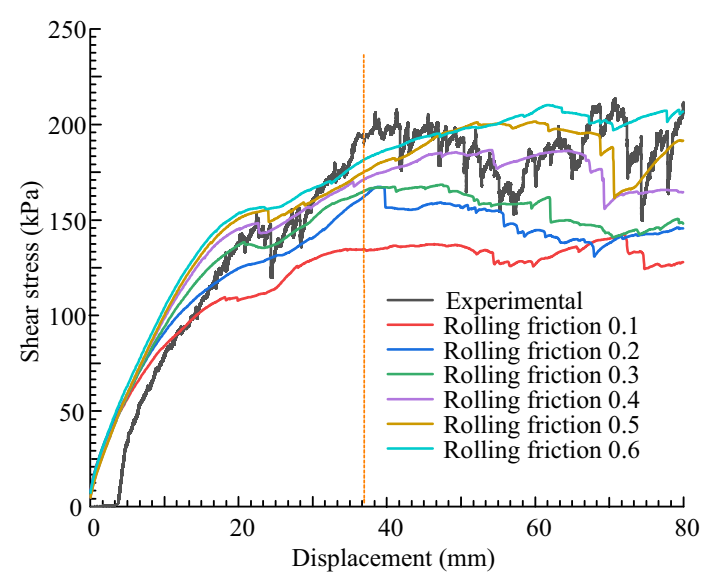

(b) Normal stress $54 \mathrm{kPa}$

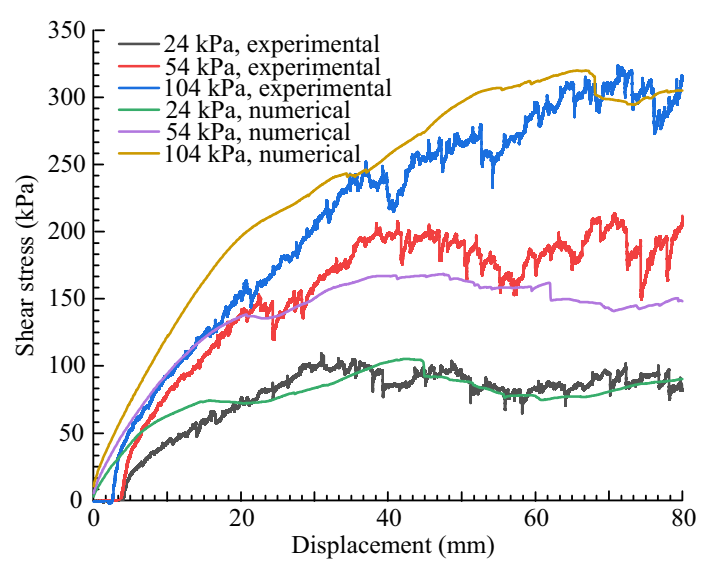

(d) Rolling friction 0.3

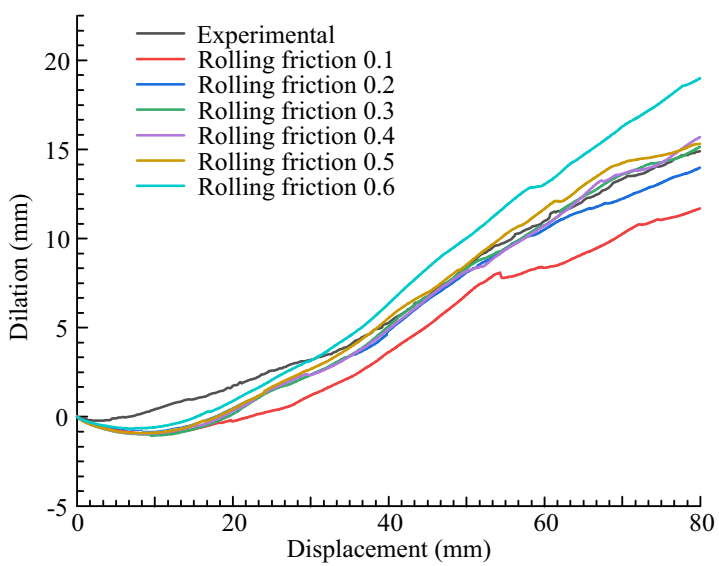

(f) Normal stress $54 \mathrm{kPa}$

Fig. 5 Shear stress and dilation results of the DST simulation under the normal stress of 24,54 or $104 \mathrm{kPa}$

the two stiffness (normal and shear) are calibrated. For the LPST model with non-spherical particles, the LC model is used and the results are compared with those of the DST model with spheres. The applied cyclic loading frequency is $20 \mathrm{~Hz}$ and it is a sinusoidal loading from 50 to $460 \mathrm{kPa}$. 


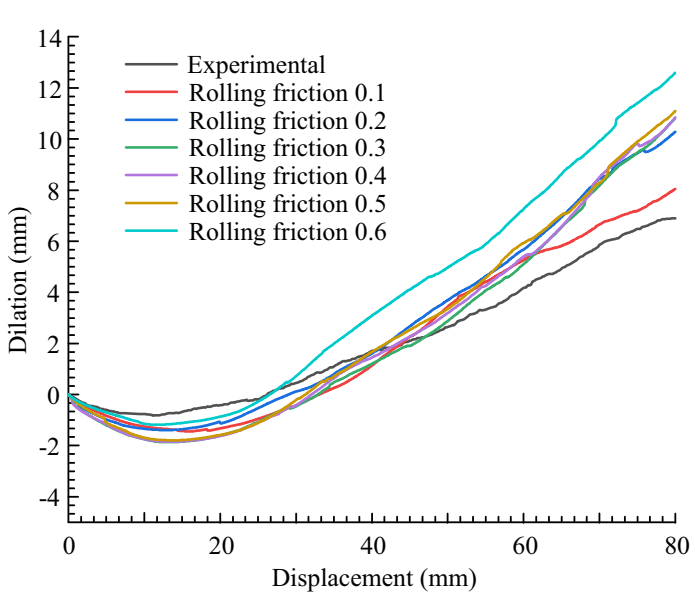

(g) Normal stress $104 \mathrm{kPa}$

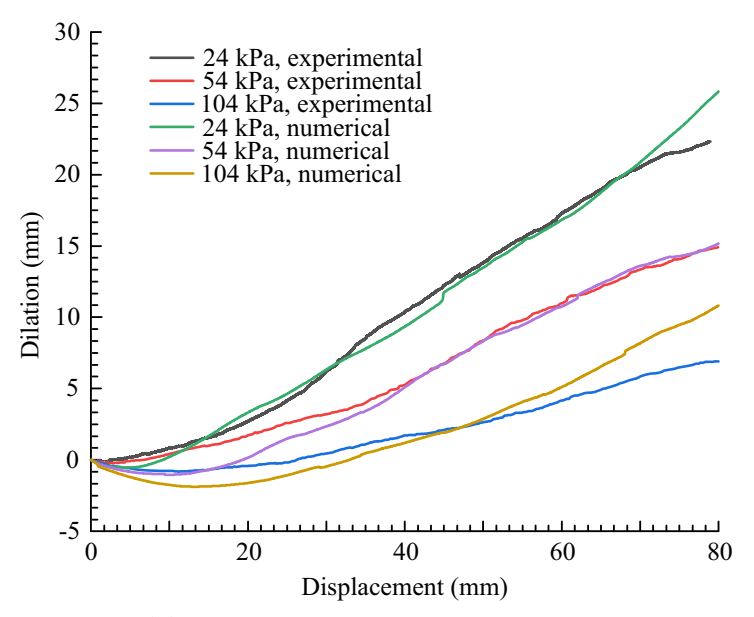

(h) Normal stressand rolling friction 0.3

Fig. 5 continued

\section{Results and discussion}

\subsection{DST simulation results}

\subsubsection{Contact model}

Figure 4 presents the shear stress and deformation results of the DST model with sphere. The rolling friction coefficient is set as 0.1 , and the normal stress is $24 \mathrm{kPa}$.

From Fig. 4a and b, it can be seen that the peak shear stress increases with the stiffness; however, it increases slightly and stays at around $60-70 \mathrm{kPa}$ after the stiffness is over $4 \times 10^{5}$. Moreover, the peak shear stress is reached with shorter horizontal box displacement, when the contact stiffness is increased from $5 \times 10^{5}$ to $1 \times 10^{7}$. Figure $4 \mathrm{c}$ and $\mathrm{d}$ presents the deformation results at different stiffness values. They illustrate that lower stiffness will cause significant shear contraction, and higher stiffness can lead to deformation results more similar to the experimental test, i.e. $4 \times 10^{5}, 5 \times 10^{5}, 1 \times 10^{6}$ and $1 \times 10^{7}$. Based on the above results, it can be seen that the shear peak stress increases with the stiffness, but for the model with sphere and low rolling friction (0.1) it does not agree with the experimental shear peak stress. In addition, it is reasonable that the peak shear stress appears when the shear displacement is $30 \mathrm{~mm}$.

Particularly, lower stiffness leads to less computation time. For example, using the spheres with the stiffness at $1 \times 10^{5}$ and $1 \times 10^{7}$ take the computation time of 433 and $1242 \mathrm{~s}$, respectively. In the same test condition, using the sphere, 5-sphere clump, 12-sphere clump and 23-sphere clump take the computation time of $51,80,306$ and 400 min, respectively. This means using the spheres is 8 times efficient at most.

In Fig. $4 \mathrm{e}-\mathrm{h}$ and $\mathrm{i}-\mathrm{l}$, the shear stress and deformation results with increasing rolling friction are presented. From the shear stress results, it can be observed that the peak shear stress considerably increase with the rolling friction, and ballast assemblies with higher rolling friction needs larger shear displacement to reach the peak shear stress. Another fact is that with the higher stiffness, the peak shear stress increases at a faster rate than the rolling friction. From the deformation results, it can be seen that the deformation increases with the rolling friction, and high stiffness can cause large deformation change under the increasing rolling friction. Through comparing the experimental results with simulation ones in Fig. 4, we find that the stiffness of $4 \times 10^{5}$ can be chosen as the most suitable value for the DST model.

Based on the above results, both normal and shear stiffness take the value of $4 \times 10^{5}$. Nevertheless, we design the following simulation conditions to validate this value. The DST simulations under different normal stresses are performed and the results of shear stress and deformation are shown in Fig. 5.

Figure $5 \mathrm{a}-\mathrm{c}$ present the shear stress results under the normal stress of 24,54 and $104 \mathrm{kPa}$, respectively, and Fig. $5 \mathrm{~d}$ presents the shear stress with the rolling friction of 0.3 . From the figure, it can be seen that with the stiffness of $4 \times 10^{5}$, the shear stress results under three normal stresses are consistent with the experimental ones. More importantly, it is shown that the rolling friction value of 0.3 can be selected for the following simulations that change particles with different shapes (clumps).

\subsubsection{Particle shape}

3.1.2.1 Shear stress and deformation In Fig. 6, the shear stress and deformation of the model with the spheres are 


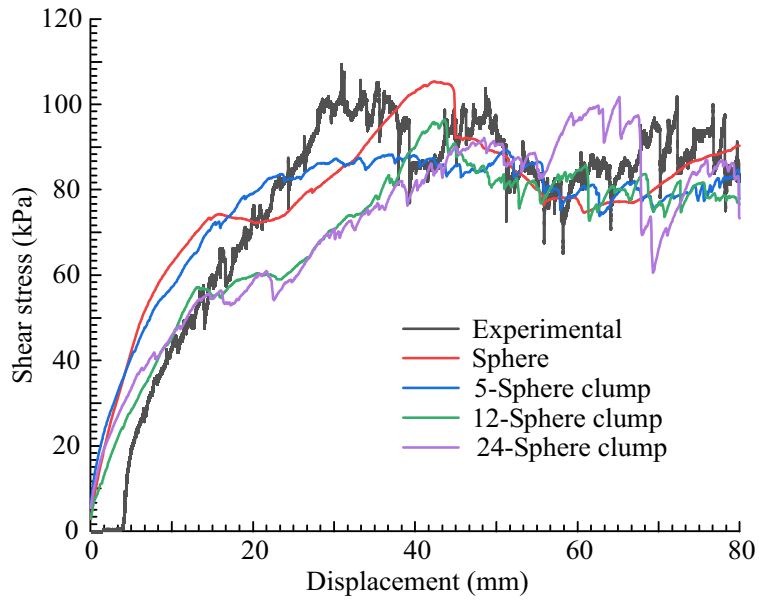

(a) Normal stress $24 \mathrm{kPa}$

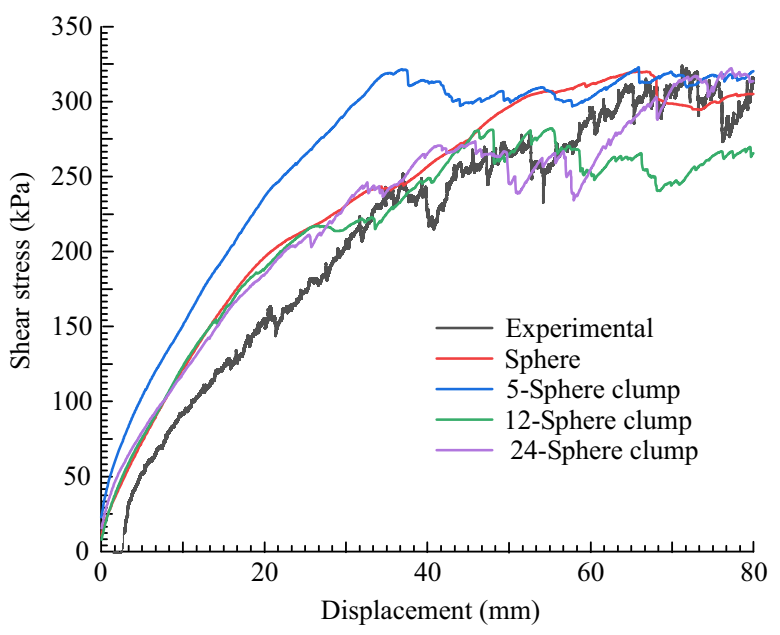

(c) Normal stress $104 \mathrm{kPa}$

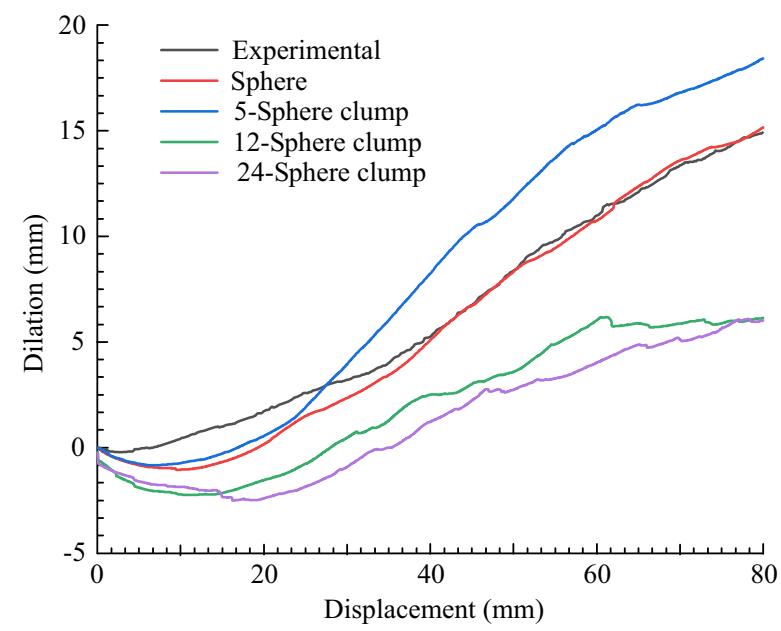

(e) Normal stress $54 \mathrm{kPa}$

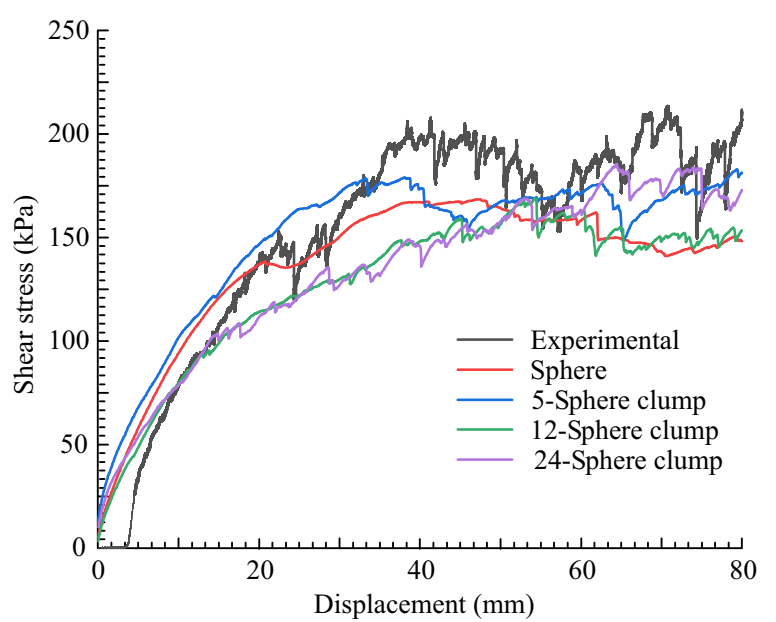

(b) Normal stress $54 \mathrm{kPa}$

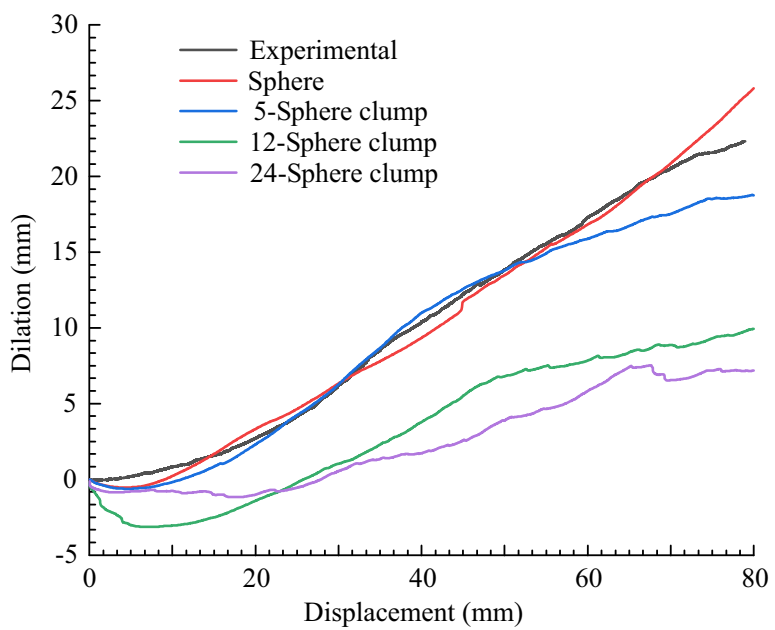

(d) Normal stress $24 \mathrm{kPa}$

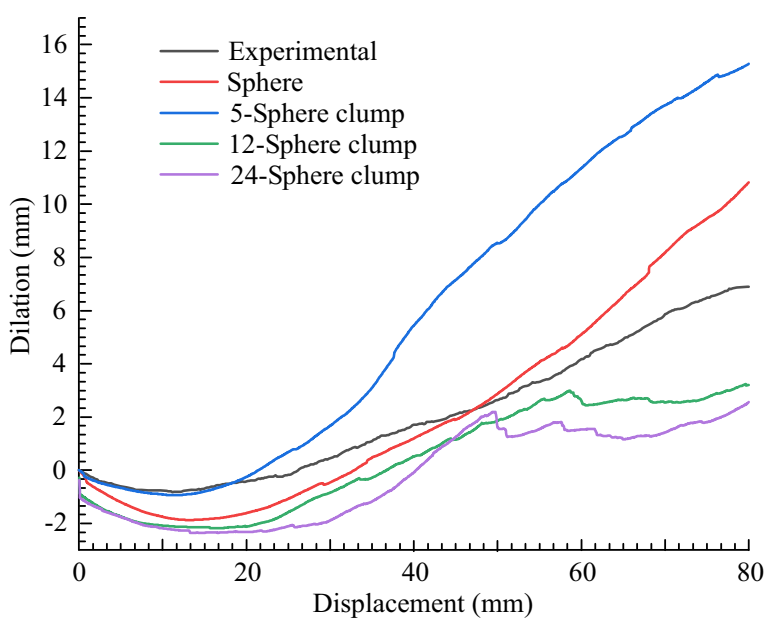

(f) Normal stress $104 \mathrm{kPa}$

Fig. 6 Shear stress and dilation results of the DST simulation with different particles 


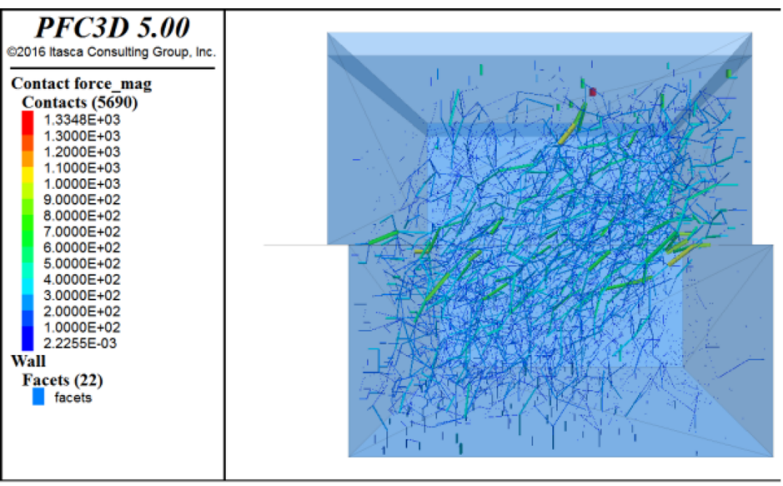

(a) 5-Sphere clump, $104 \mathrm{kPa}, 20 \mathrm{~mm}$

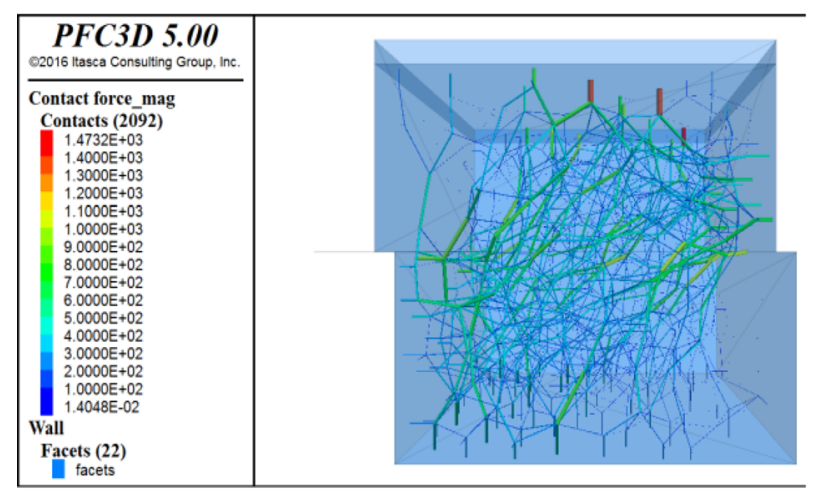

(c) 23-Sphere clump, $104 \mathrm{kPa}, 20 \mathrm{~mm}$

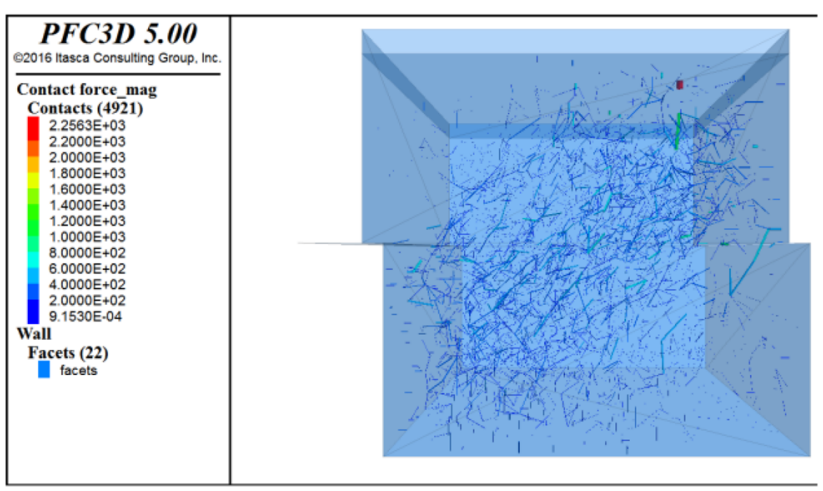

(b) 12-Sphere clump, $104 \mathrm{kPa}, 20 \mathrm{~mm}$

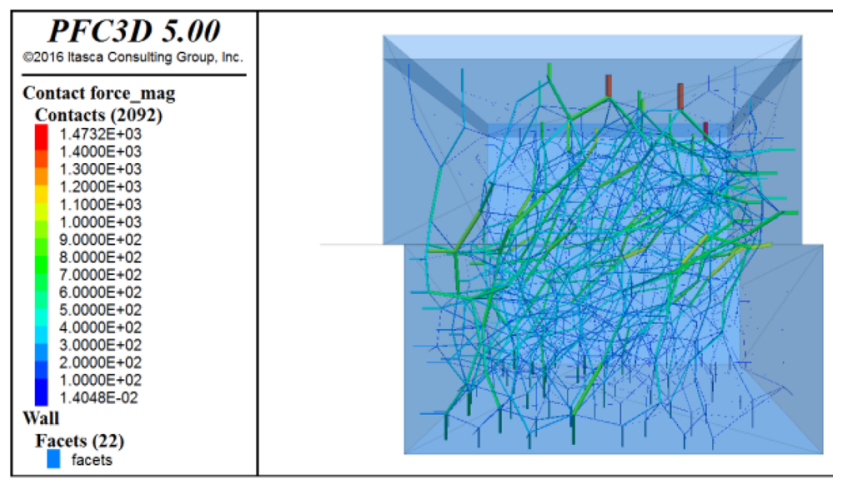

(d) Sphere, $104 \mathrm{kPa}, 20 \mathrm{~mm}$

Fig. 7 Force chain results of the DST simulation under the normal stress $104 \mathrm{kPa}$ and shearing displacement $20 \mathrm{~mm}$

compared with those of the ones with the clumps (5-, 12- or 23 -sphere) and the experimental one. For the spheres, the stiffness is $4 \times 10^{5}$ and the rolling friction is 0.3 (the RRL model). For the clumps, the stiffness is $4 \times 10^{5}$ and no rolling friction is applied (LC model). From Fig. 6a-c, it can be observed that for the RRL model (i.e. applying rolling friction), the simple sphere and complex shapes (clumps) have similar shear stress results. In addition, it can be observed that the shear stress of the 12-sphere clump is almost the same as that of the 23-sphere clump, but under the normal stresses of 54 and 104, their peak shear stress values are lower than that of the 5-sphere clump.

From Fig. 6d-f, it can be observed that the deformation results for using the sphere can better accord with the experimental results than those for using the clump. The 5 -sphere clump deformation is higher than the deformation of other two types of clump. The 23 -sphere clump has the most realistic shape, but it provides the lowest deformation, which is much lower than the experimental ones.

It is indicated that spheres with rolling friction can replace complex-shaped particles (clumps). Interestingly, it is found that the 23-sphere clump sample provides lower shear stress than the 5-sphere clump sample. This means the interlocks of the 5-sphere clump is stronger than the 23-sphere clump, as some particles link each other to become one big particle. The rolling friction has the same effects as strengthening the contacts and acting as the interlocks.

For further testing the vertical settlement and lateral deformation of the sphere with rolling friction, the LPST model is developed. The simulation results are compared with the clumps and the results from Ref. [18].

3.1.2.2 Contact force analysis The contact force analysis is crucial for observing the differences of different particle shapes and contact models at the mesoscopic level. Most of the earlier studies utilised the criterions at the macroscopic level, such as the shear strength in the DST (or triaxial test) [38], and the friction angle in the hopper discharge [37]. They compared the shear stress and strain or the repose angle to present that the parameters in the model can be confirmed. However, different parameters can similarly match the same test results. In other words, large difference in the parameters of the contact model may still lead to similar response. For this reason, the analysis at the mesoscopic level is necessary to perform with respect to the contact force chain, contact force distribution, and coordination number. 


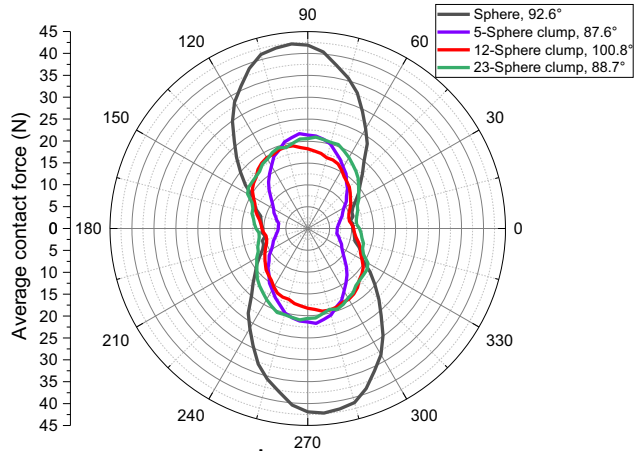

(a) Displacement $0 \mathrm{~mm}$

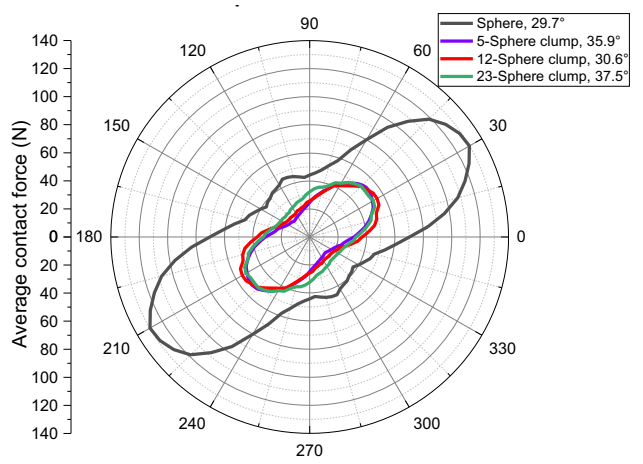

(c) Displacement $40 \mathrm{~mm}$

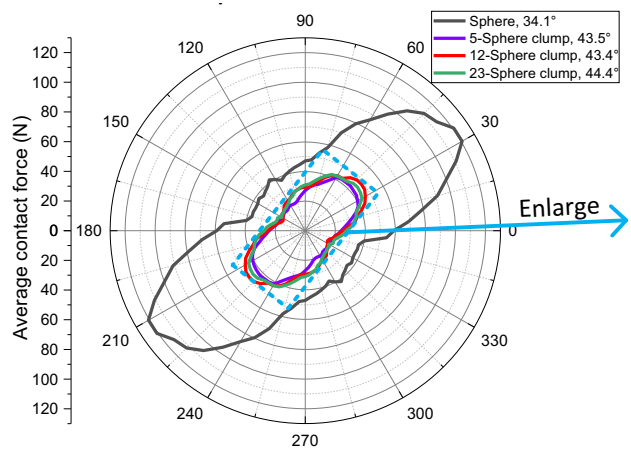

(e) Displacement $80 \mathrm{~mm}$

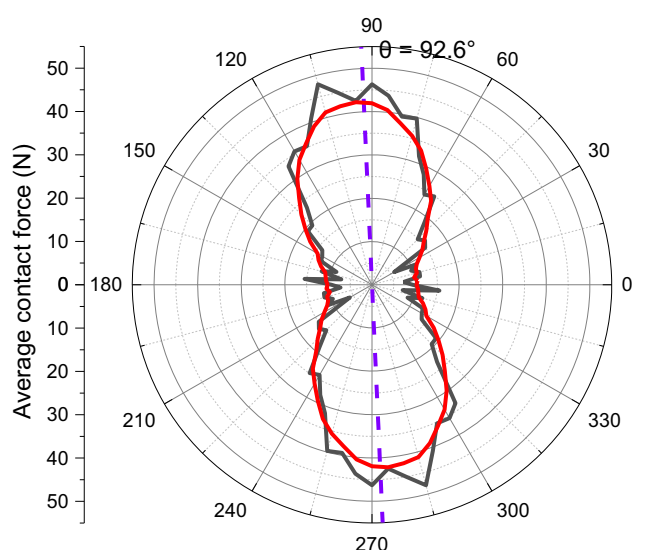

(g) Example of the diagram

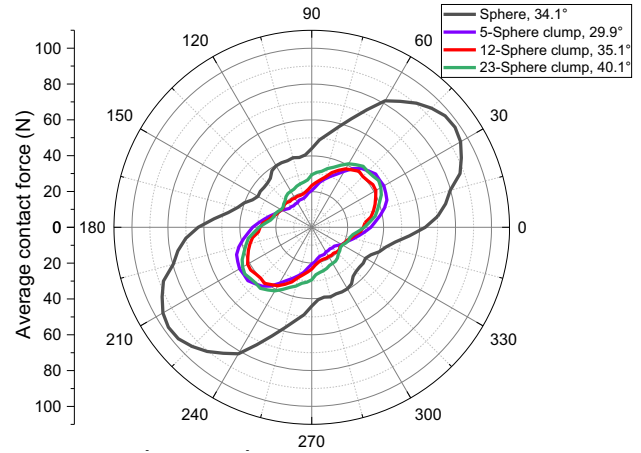

(b) Displacement $20 \mathrm{~mm}$

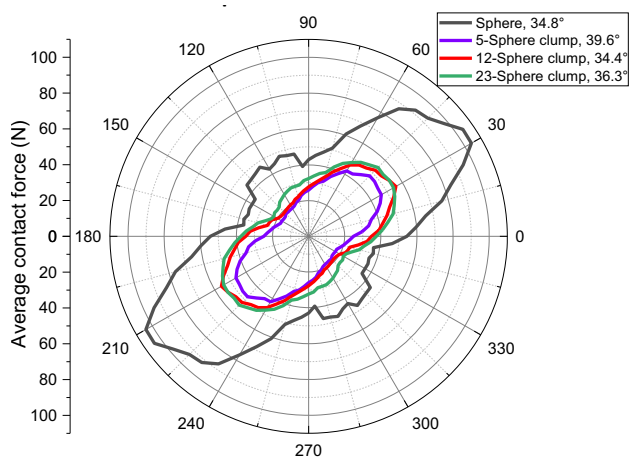

(d) Displacement $60 \mathrm{~mm}$

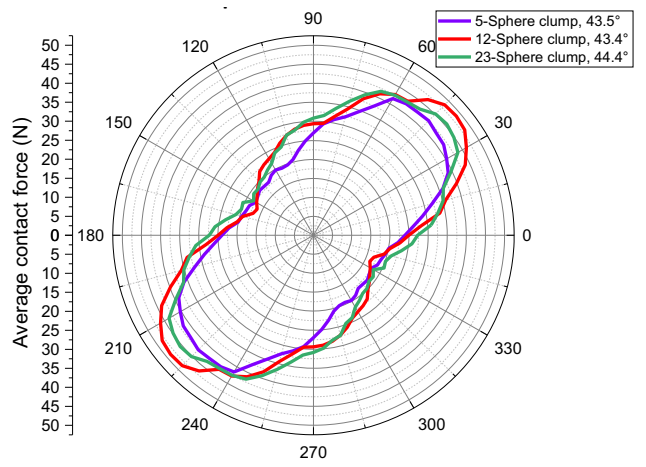

(f) Enlarged figure

Fig. 8 Distributions of the particle normal contact forces under the normal stress $24 \mathrm{kPa}$ 


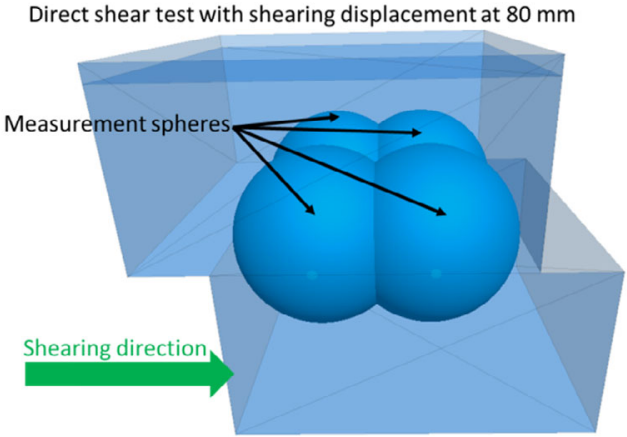

(a) Positions for coordination number calculation

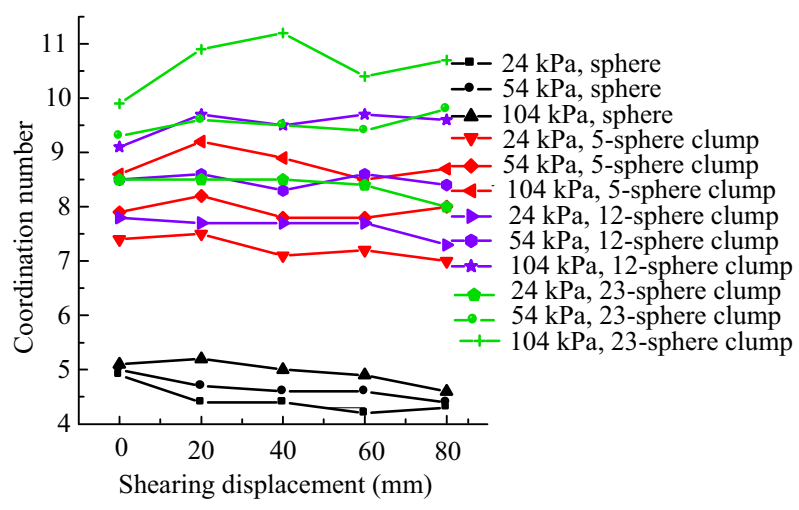

(b) Coordination number comparison

Fig. 9 Coordination number comparison of the sphere and clump

3.1.2.3 Contact force chain The contact force chain is used for observing the force transmit and the shear band. The force chain results of the DST simulation are shown in Fig. 7, where the shear band with the spheres are wider than that with the clumps. The largest contact force values are close, but the model with the spheres has large average contact forces and clear force chain. This can also be observed in the other conditions with the shearing displacements of $80 \mathrm{~mm}$ and normal stresses of $54 / 24 \mathrm{kPa}$ (Fig. 14, "Appendix"). This is because using the spheres reduce the numbers of particles and contacts, and then each contact contributes larger forces.

For easy comparison, contact force anisotropy and their distribution are shown in Fig. $8 \mathrm{~g}$ by the rose diagrams. In Fig. 8, the contact force under the normal stress of $24 \mathrm{kPa}$ with 5 different shearing displacements $(0$ and $80 \mathrm{~mm})$ is presented, and all the rose diagrams are given in Fig. 15.

In Fig. 8g, the average contact force is calculated from the projected forces. The contact forces are projected to the $Y Z$ plane, and the $Y$-axis directs the shearing direction, as shown in Fig. 1b. The $Y Z$ plane is chosen as the shearing direction has the most apparent contact force chain change during shearing.

The average contact force is calculated by averaging the forces within a certain angle range (every five degrees). Specifically, the forces have a direction vector that has an angle to the $Y$-axis. While $360^{\circ}$ are divided every $5^{\circ}$ into 72 ranges, the forces with the direction vectors in one range are averaged. The points in every ranges are connected to form one closed curve like the black curve in Fig. 8g. The red curve in Fig. 8g is obtained by smoothing the closed curve for observing the primary orientation more easily. The primary orientation is the purple line drawn by evaluating the direction of the red curve. Specifically, the purple line separates the area into two equal ones.

From this figure, it can be seen that with the increase of the shearing displacement, the primary orientation decreases from around $90^{\circ}(0 \mathrm{~mm})$ to the lowest $\left(29.7^{\circ} \%\right.$ $29.9^{\circ} / 30.6^{\circ} / 36.3^{\circ}$ ); afterwards, the value slightly increases. Note that the lowest primary orientation with the spheres is approximately the same as that with the clumps except for the 12-sphere clump.

What is more, the contact force with the spheres is $2-2.5$ times larger than that with the clumps. However, the average contact forces are approximately the same for the models with the clumps (Fig. 8e, f). For example, in Fig. 8 b, the largest average contact force with the sphere is around $100 \mathrm{~N}$, and the smallest is around $40 \mathrm{~N}$. Correspondingly, the models with clumps produce the maximum and minimum values of $40-50 \mathrm{~N}$ and $15-25 \mathrm{~N}$, respectively. It can also be seen that the average contact forces increase with the shearing displacement.

It is significant to find that the average contact force of the spheres is 2-2.5 times larger than that of the clumps. This is because the contacts of the spheres are approximately half of the clumps, and thus every contact bear more shearing stress. Alternatively, every contact of the spheres are strengthened. The contact number of each particle can be presented by the coordination number, which will be discussed in the following section.

3.1.2.4 Coordination number The comparison of coordination number change is shown in Fig. 9b. The coordination number is the average number of active contacts for each particle. The coordination number is calculated by the use of the particles that lie at the shearing zone within the four measurement spheres, as shown in Fig. 9a. As the shearing zone is the most important position to produce the shearing stress, the particles at the shearing zone have the most obvious movements. The radius of the measurement spheres is $0.1 \mathrm{~m}$, and the coordinates of the measurement spheres are $(0.1,0.18,0.2),(0.3,0.18,0.2),(0.1,0.3,0.2)$ and $(0.3,0.3,0.2)$.

From Fig. 9, it can be seen that the coordination number increases as the particle shape is more complex (from spheres to clumps). Moreover, with the increase of the 


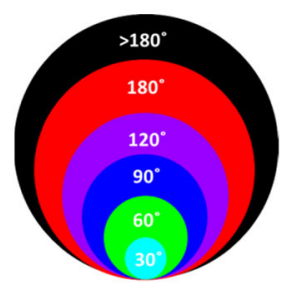

(a) Colours for different rotation magnitudes

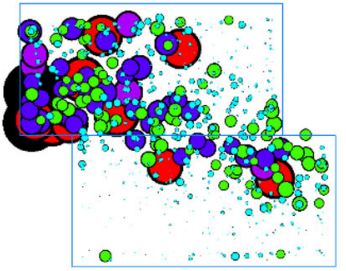

(e) $104 \mathrm{kPa}$; sphere; displacement $80 \mathrm{~mm}$

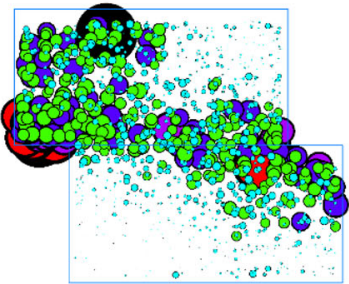

(i) $104 \mathrm{kPa}$; 5 -sphere clump; displacement $80 \mathrm{~mm}$

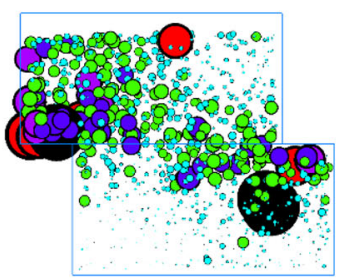

(m) $104 \mathrm{kPa}$; 12-sphere clump; displacement $80 \mathrm{~mm}$

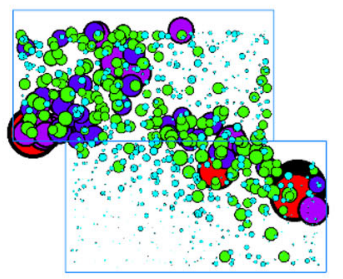

(q) $104 \mathrm{kPa}$; 23-sphere clump; displacement $80 \mathrm{~mm}$

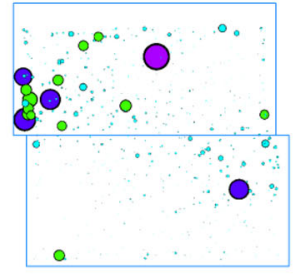

(b) $104 \mathrm{kPa}$; sphere;

displacement $20 \mathrm{~mm}$

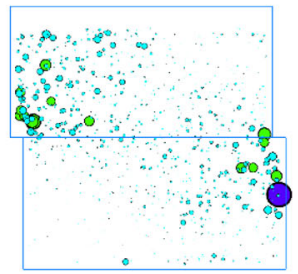

(f) $104 \mathrm{kPa}$; 5 -sphere clump; displacement $20 \mathrm{~mm}$

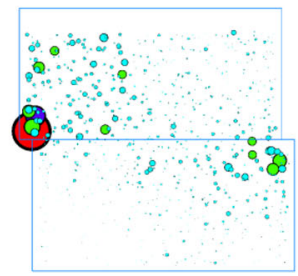

(j) $104 \mathrm{kPa}$; 12-sphere clump displacement $20 \mathrm{~mm}$

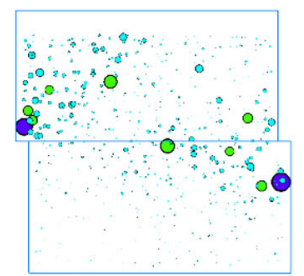

(n) $104 \mathrm{kPa}$; 23-sphere clump; displacement $20 \mathrm{~mm}$

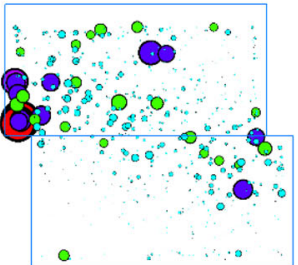

(c) $104 \mathrm{kPa}$; sphere; displacement $40 \mathrm{~mm}$

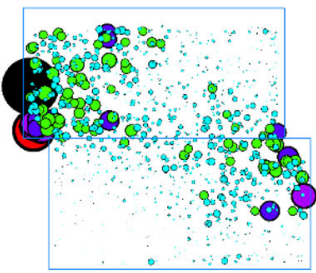

(g) $104 \mathrm{kPa}$; 5-sphere clump; displacement $40 \mathrm{~mm}$

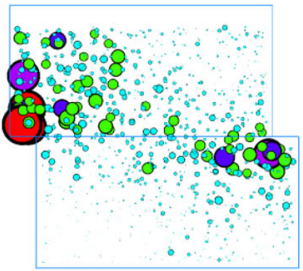

(k) $104 \mathrm{kPa}$; 12-sphere clump; displacement $40 \mathrm{~mm}$

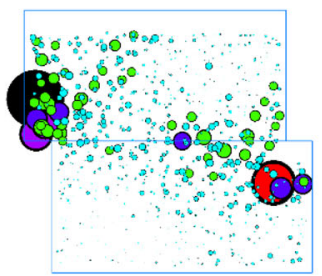

(o) $104 \mathrm{kPa}$; 23-sphere clump; displacement $40 \mathrm{~mm}$

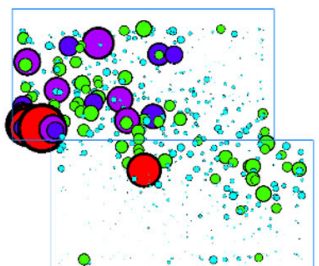

(d) $104 \mathrm{kPa}$; sphere; displacement

$60 \mathrm{~mm}$

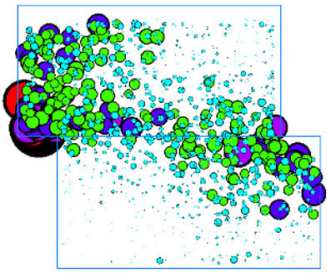

(h) $104 \mathrm{kPa}$; 5-sphere clump; displacement $60 \mathrm{~mm}$

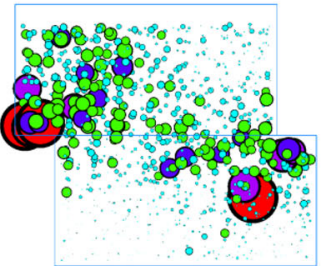

(l) $104 \mathrm{kPa}$; 12-sphere clump; displacement $60 \mathrm{~mm}$

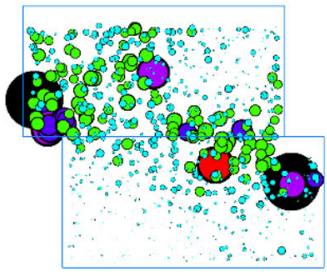

(p) $104 \mathrm{kPa}$; 23-sphere clump; displacement $60 \mathrm{~mm}$

Fig. 10 Particle rotation of using the spheres or clumps 


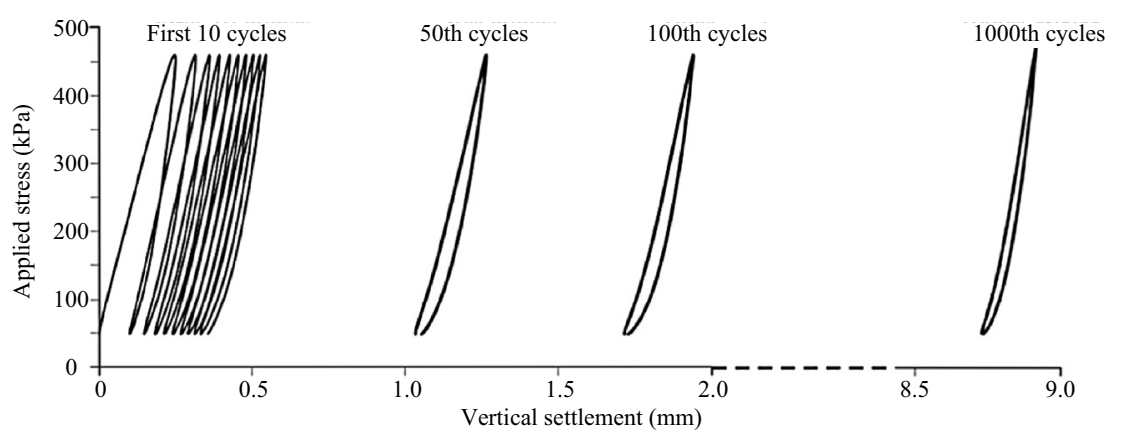

(a) Figure reproduced from [18]

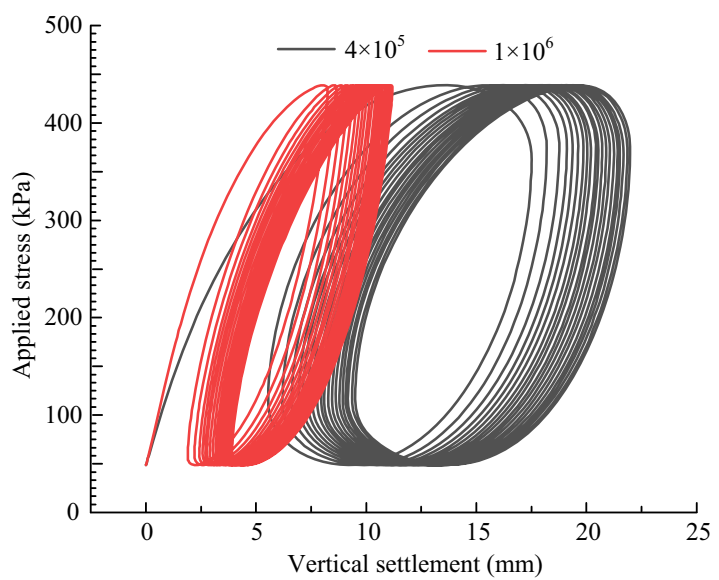

(b) Sphere with rolling friction

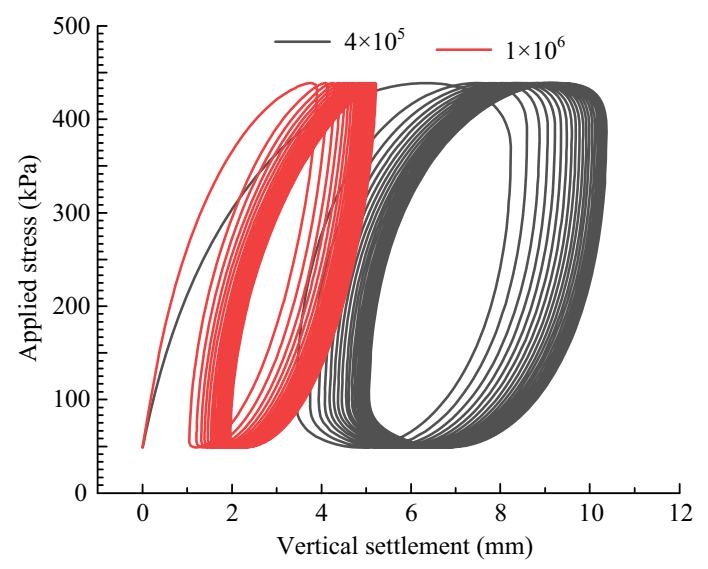

(d) 5-Sphere clump without rolling friction

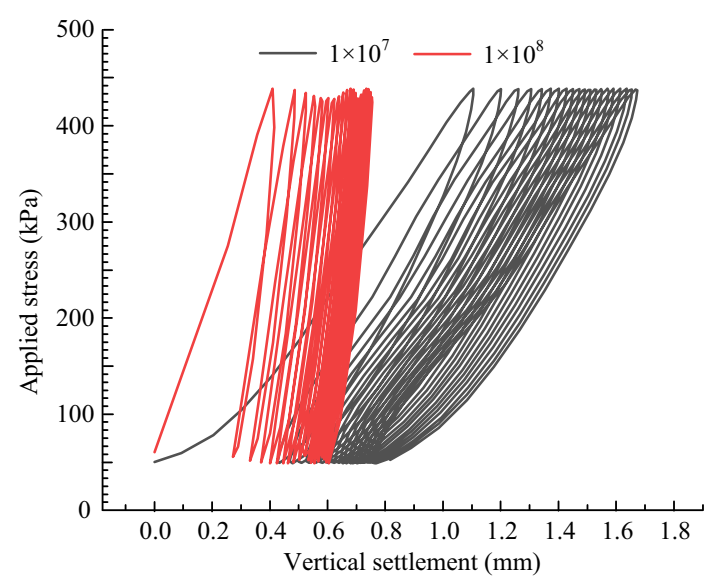

(c) Sphere with rolling friction

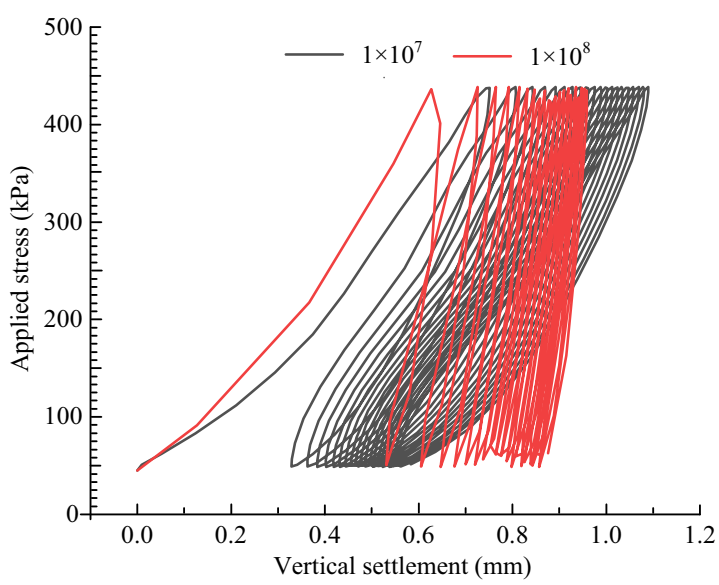

(e) 5-Sphere clump without rolling friction

Fig. 11 Applied stress vs vertical displacement in the first 15 cycles

normal stress $(24,54$, and $104 \mathrm{kPa})$, the coordination number also increases, as the assemblies are more compacted. The 23-sphere clumps can produce approximately twice coordination number than the spheres. The coordination number results demonstrate that the contacts of the spheres are less than those of the clumps.
3.1.2.5 Particle rotation In order to confirm the effects of the rolling resistance on the particle rotation, the sphere model with the RRL model is compared with the clump model with the LC model, as shown in Fig. 10. This figure illustrates the projection of all the particles' rotation on the $Y-Z$ Plane, and particularly, the $Y$-axis is the DST boxshearing direction. The circles in the DST box represent the magnitude and position of the particle rotation, and the 


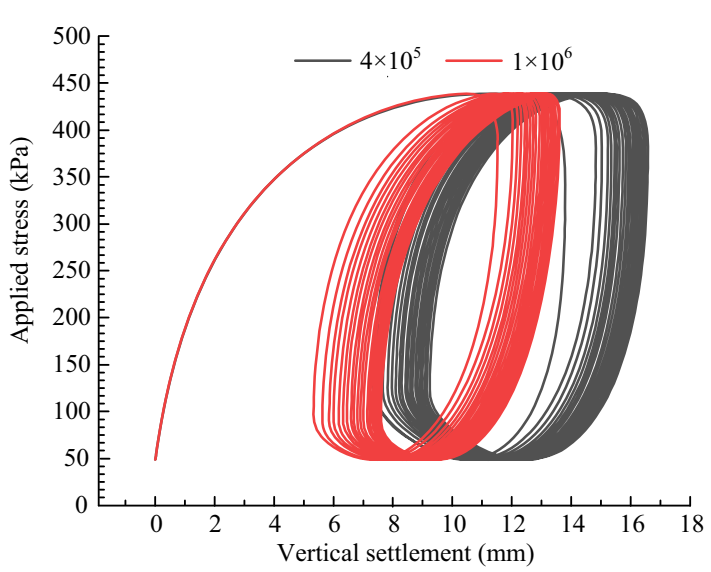

(f) 12-Sphere clump without rolling friction

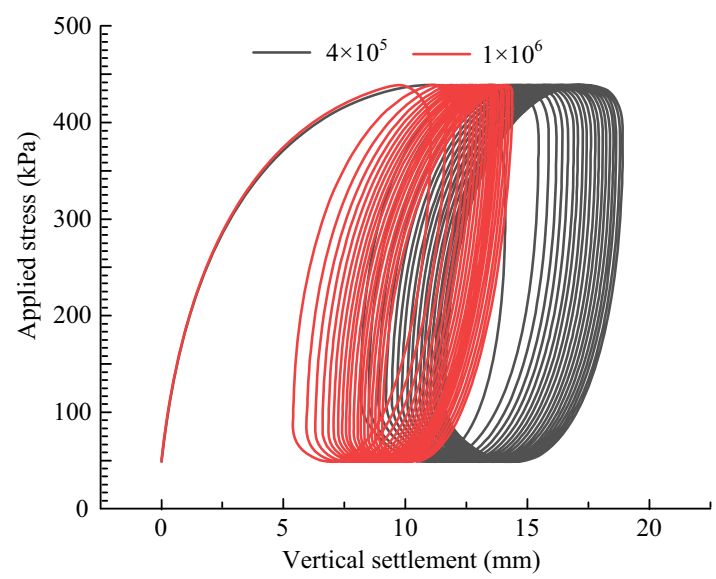

(h) 23 -Sphere clump without rolling friction

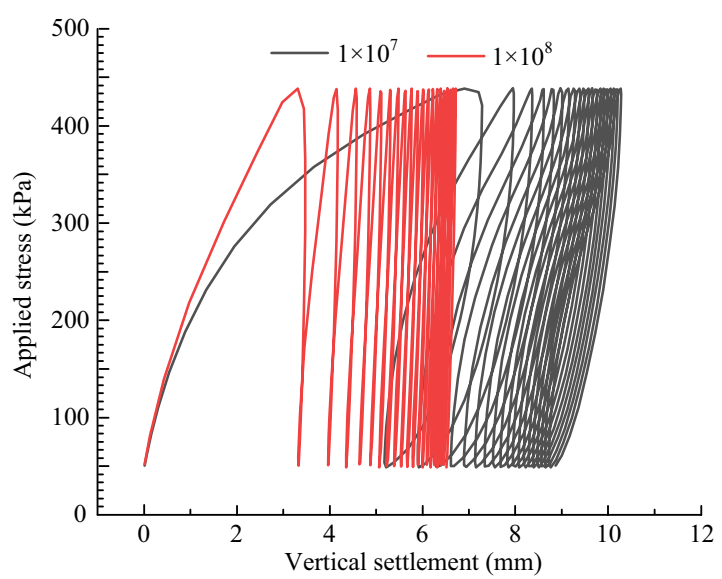

(g) 12 -Sphere clump without rolling friction

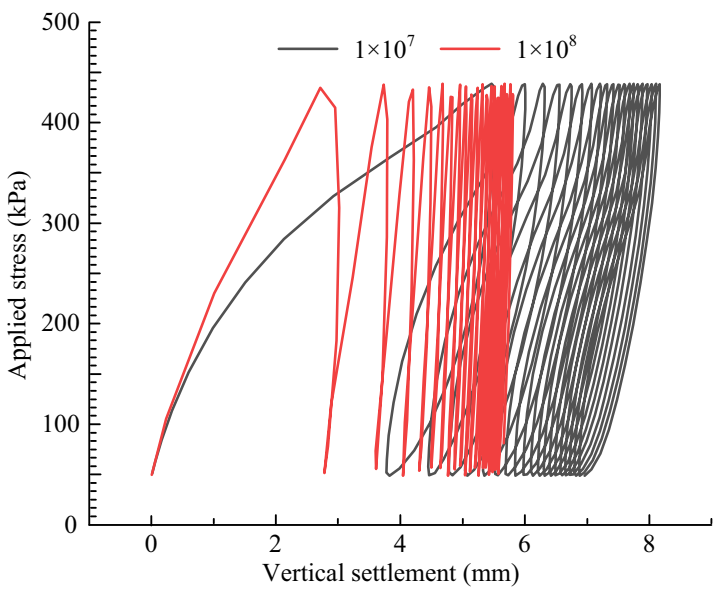

(i) 23-Sphere clump without rolling friction

Fig. 11 continued

circle colour helps to distinguish the rotation magnitude (Fig. 10a). The figure shows part of the results that are obtained under the normal stress $104 \mathrm{kPa}$, and all the particle rotation results are given in Fig. 16 ("Appendix").

The particle rotation is calculated by Eq. (1) [39]. In the equation, the Euler angles are utilised to calculate the particle rotation (i.e. $\phi, \theta$ and $\psi$ ), which present the precession rotation, nutation rotation and intrinsic rotation, respectively.

$P=\sqrt{(\theta)^{2}+(\psi)^{2}+(\varphi)^{2}}$.

From the figures, it can be observed that the particle rotation of the sphere model is almost the same as that of the clump model. Specifically, the largest rotation (over $180^{\circ}$ ) appears at the similar positions, which are the left side of the upper shear box and the right side of the lower shear box, and both of them are near the shearing interface. In addition, most of the large circles (green, purple, and red) appear along the diagonal line of the shear box and the line is approximately perpendicular to the contact chain direction.

\subsection{Large-scale process simulation test model}

\subsubsection{Stiffness and particle shape}

Figure 11 presents the applied stress vs vertical displacement with four kinds of particles and different normal and shear stiffnesses. From the figure, it can be observed that the elastic deformation and plastic deformation reduce as the stiffness increase. In addition, the results at the stiffness of $4 \times 10^{5}$ cannot accord with the results in Ref [18], where the elastic deformation and plastic deformation are within $0.5 \mathrm{~mm}$ (Fig. 11a). After the comparison, it is found that the results that correspond to the spheres or 5 -sphere clumps with the stiffness of $1 \times 10^{7}$ or $1 \times 10^{8} \mathrm{~N} / \mathrm{m}$ (Fig. $11 \mathrm{c}$, e) can approximately accord with those in [18]. This proves that using one set of contact model parameters may not be fit to all the tests, despite testing on the same material. Even though the DST is a well-known method for confirming the 


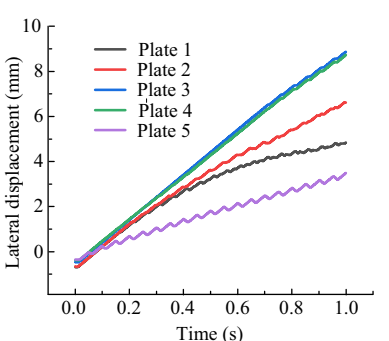

(a) Sphere with rolling friction; stiffness $4 \times 10^{5}$

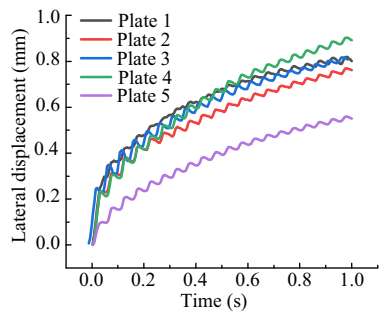

(d) Sphere with rolling friction and stiffness $1 \times 10^{8}$

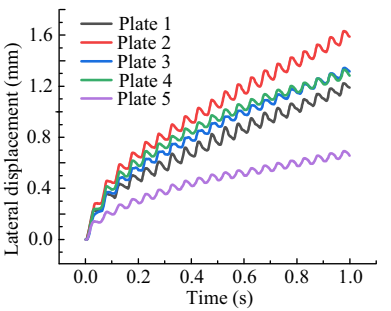

(g) 5 -Sphere clump; stiffness $1 \times 10^{7}$

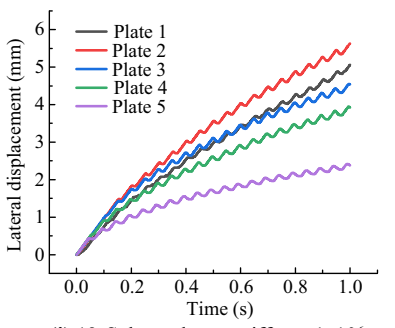

(j) 12-Sphere clump; stiffness $1 \times 10^{6}$

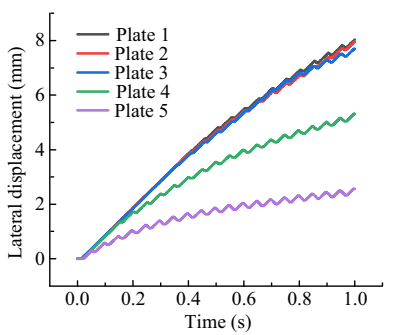

(m) 23 -Sphere clump; stiffness $4 \times 10^{5}$

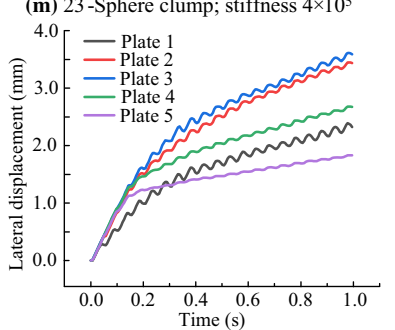

(p) 23-Sphere clump; stiffness $1 \times 10^{8}$

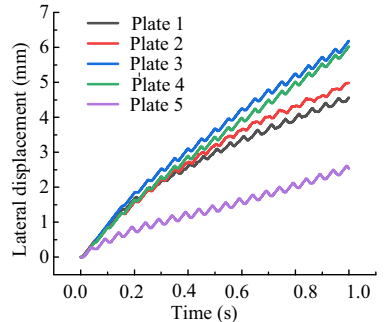

(b) Sphere with rolling friction; stiffness $1 \times 10^{6}$

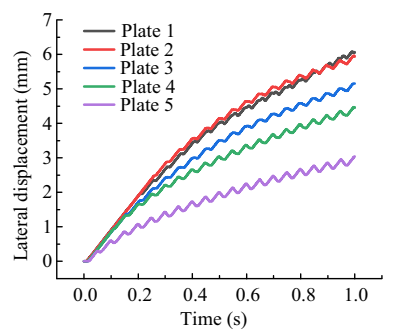

(e) 5-Sphere clump; stiffness $4 \times 10^{8}$

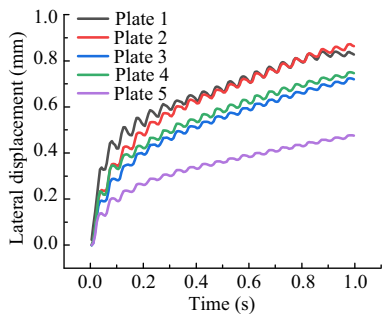

(h) 5 -Sphere clump; stiffness $1 \times 10^{8}$

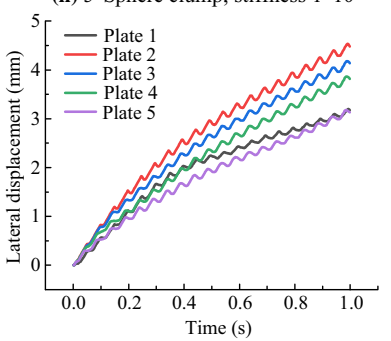

(k) 12-Sphere clump; stiffness $1 \times 10^{7}$

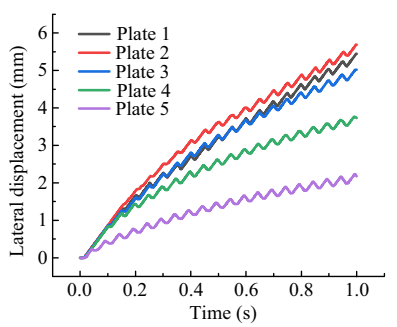

(n)23-Sphere clump; stiffness $1 \times 10^{6}$

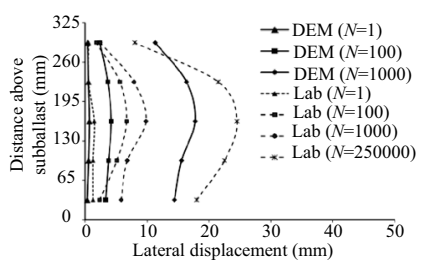

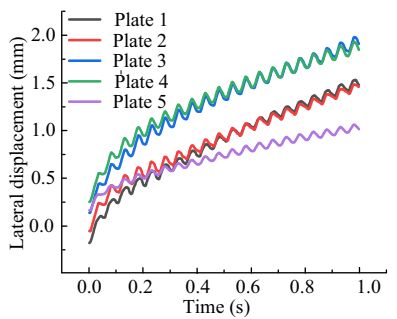

c) Sphere with rolling friction; stiffness $1 \times 10^{7}$

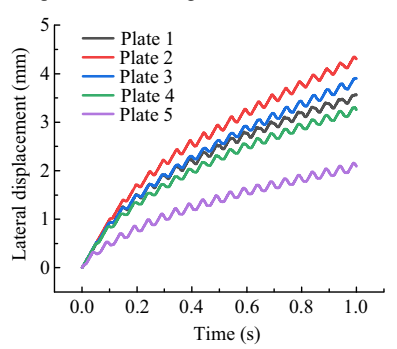

(f) 5-Sphere clump; stiffness $1 \times 10^{6}$

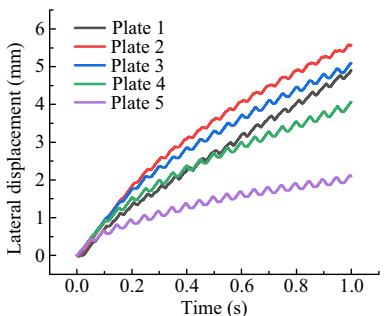

(i) 12 -Sphere clump; stiffness $4 \times 10^{5}$

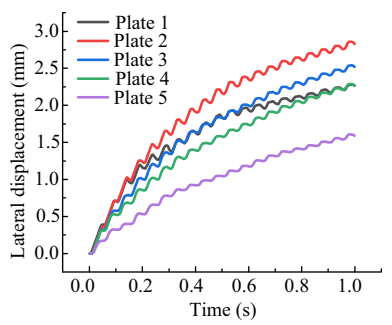

(I) 12 -Sphere clump; stiffness $1 \times 10^{8}$

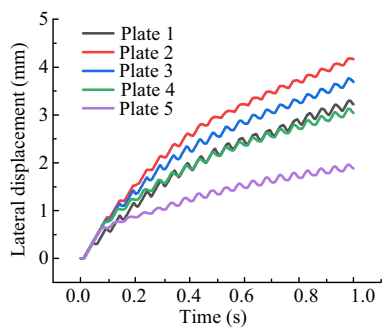

(o) 23 -Sphere clump; stiffness $1 \times 10^{7}$

(q) Figure reproduced from [18]

Fig. 12 Lateral displacement vs time of the five movable plates and the reference form literature [18] 

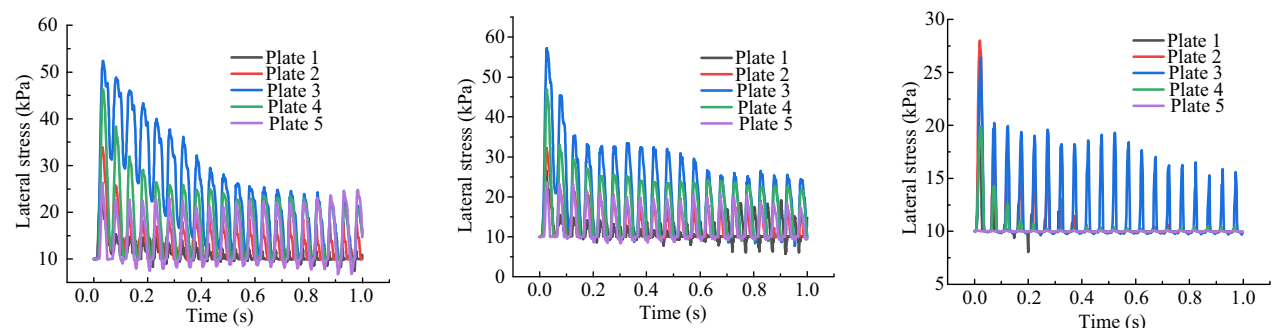

(a) Sphere with rolling friction; stiffness $4 \times 10^{5}$ (b) Sphere with rolling friction; stiffness $1 \times 10^{6}$

(c) Sphere with rolling friction; stiffness $1 \times 10^{7}$
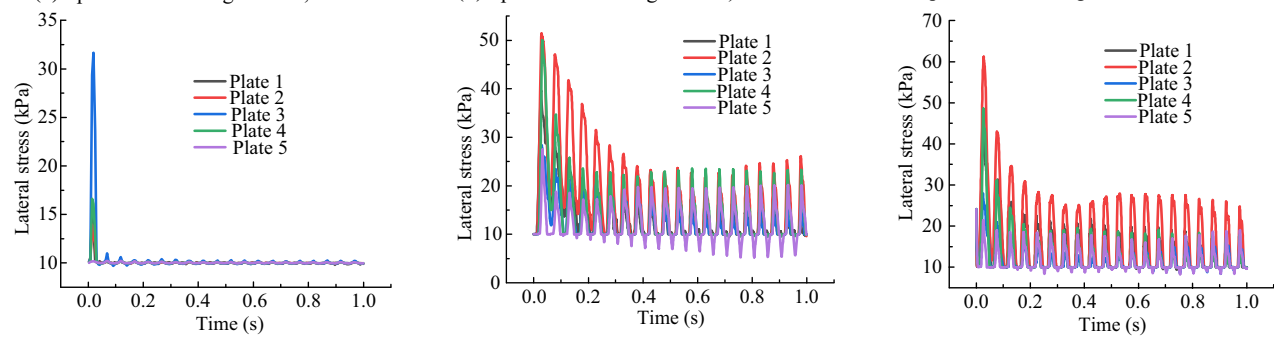

(d) Sphere with rolling friction; stiffness $1 \times 10^{8}$

(e) 5 -Sphere clump; stiffness $4 \times 10^{5}$

(f) 5 -Sphere clump; stiffness $1 \times 10^{6}$
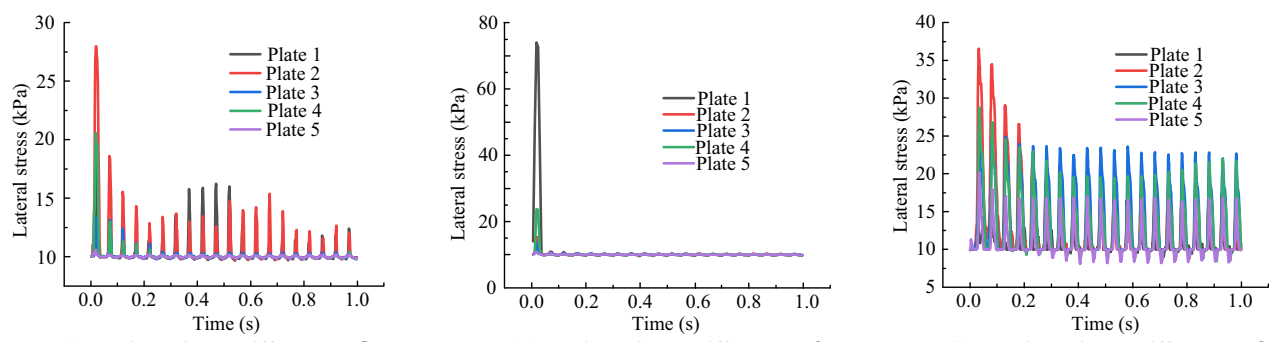

(g) 5 -Sphere clump; stiffness $1 \times 10^{7}$

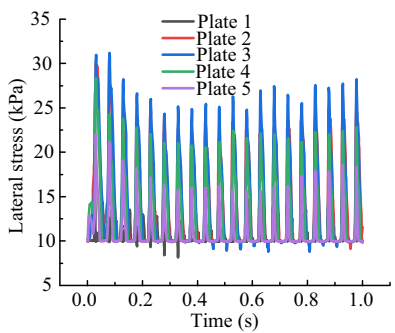

(h) 5 -Sphere clump; stiffness $1 \times 10^{8}$

(i) 12 -Sphere clump; stiffness $4 \times 10^{5}$
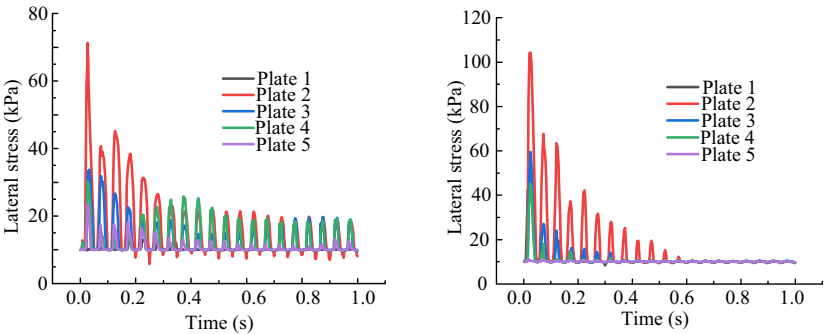

(k) 12-Sphere clump; stiffness $1 \times 10^{7}$

(l) 12 -Sphere clump; stiffness $1 \times 10^{8}$
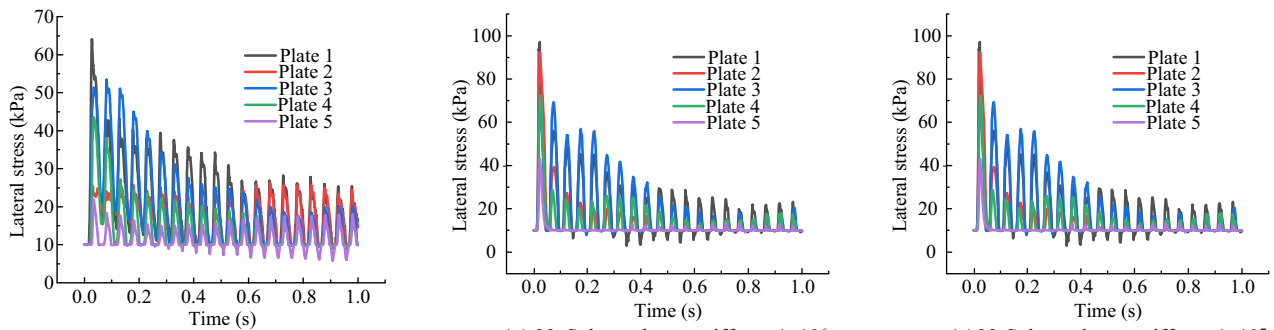

(n) 23 -Sphere clump; stiffness $1 \times 10^{6}$

(o) 23 -Sphere clump; stiffness $1 \times 10^{7}$

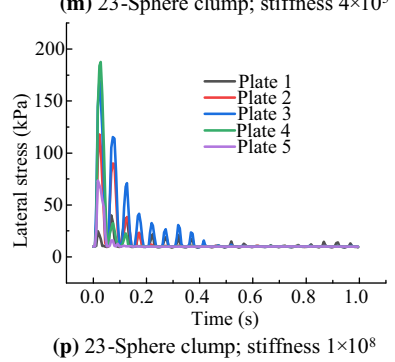

Fig. 13 Lateral stress vs time of the five movable plates 
parameters in the numerical models, an extra test should be applied for confirming if the parameters are suitable for all tests.

Additionally, it also demonstrates that the sphere model with rolling friction can have the same or even better performance compared with the clump model. Particularly, the hypothesis of the interlocks (Sect. 3.1.2) can be proved again by comparing the results in Fig. 11c, e, g and i. Specifically, the spheres with rolling friction has less vertical deformation than the clumps. Moreover, the 5-sphere clump has less deformation than the 12-sphere clump and 23-sphere clump.

The stiffness cannot be $1 \times 10^{7}$ or $1 \times 10^{8}$ due to two facts: (1) the initial stage (before applying loadings) of ballast particle in the numerical simulation plays an important role on the first a few cycles. This can be illustrated from Fig. 11, showing that the first cycle has the largest deformation than the other following cycles. In addition, there is large deformation in the first 5 cycles; afterwards, the deformation becomes small and stable, which means the contacts between the sleeper and the ballast particles become more and the ballast particles near the sleeper are rapidly compacted. (2) The elastic deformation and plastic deformation values have a large range due to the discrete nature of railway ballast [43, 44]. In response to this, the lateral displacement and stress results of five movable plates are presented and compared with the results in [18].

\subsubsection{Lateral displacement and stress}

The lateral displacement results of the five movable plates are shown in Fig. 12, and their stress results are shown in Fig. 13. From Fig. 12a-d, it can be seen that the lateral displacements reduce with the stiffness increase. According to Fig. 12q, after 100 cycles, the lateral displacements of all five movable plates are within $5 \mathrm{~mm}$. To match the test lateral displacements, the stiffness values of $4 \times 10^{5}$ and $1 \times 10^{6}$ are not suitable for the LPST model.

Particularly, the stress from the five movable plates become a constant $(10 \mathrm{kPa})$ for the stiffness of $1 \times 10^{8}$, as shown in Fig. 13d, h, 1, and p. This demonstrates that the sphere with rolling friction can provide adequately reliable results. To be more specific, in Fig. 13d, the stresses become stable from $32 \mathrm{kPa}$ to $10 \mathrm{kPa}$ after one cycle, while the other particle shapes stabilize from much higher values, $75 \mathrm{kPa}$ (5-sphere clump), $105 \mathrm{kPa}$ (12-sphere clump) and $185 \mathrm{kPa}$ (23-sphere clump). In addition, the 12-sphere clump and 23 -sphere clump need more cycles to become stable, 11 and 9 cycles, respectively.

\section{Conclusions}

To increase the DEM simulation efficiency, the DEM models for the DST and the LPST are developed and applied to analyse the ballast performance in terms of shear strength and deformation. The efficiency of different contact model types and particle shapes are studied. The numerical results are compared with the experimental results and results from the literature. From the results and discussion, the following conclusions can be summarised:

1. Using spheres and linear rolling resistance model with properly chosen parameters, it is possible to simulate ballast performance accurately. The parameters can be confirmed by comparing the modelling results with the experimental tests.

2. The RRL model can limit the particle movements by enhancing the forces at the contacts between particles, complex shape particles with the LC model can achieve the same performance in this way.

3. The macroscopic ballast performance (e.g. shear strength) is dependent on the particle contact at the mesoscopic level (i.e. coordination number). The performance differences of the different particle shapes are mainly decided by the coordination number.

4. After calibrating the contact model parameters of a test model, the numerical results can be quite approximate to the experimental ones; nevertheless, the calibrated parameters may not be available for other test models.

5. The DEM models with spheres and the RRL model can present similar macro performance with those with clumps if model parameters have suitable values. Nevertheless, these models have quite different particle scale performance; e.g. there are still large discrepancies among the particle performances (movements) in these models.

The LPST model was tested in 15 loading cycles, and it is necessary to observe the long-term deformation performance after thousands of cycles. Additionally, the spheres with the rolling friction can lead to the same results as those from the tests; however, the detailed reasons and mesoscopic mechanics at the particle contacts can be analysed deeper in a way of the DEM simulations. It should be emphasised that the contact model parameters need further investigations to settle the most suitable ones. Finally, the particle degradation has not been considered in this work, and further studies will be performed in this respect.

Acknowledgements The research was supported by the China Scholarship Council and the Natural Science Foundation of China (Grant No. 51578469). We also would like to acknowledge the support of the Chinese Program of Introducing Talents of Discipline to 
Universities (111 Project, Grant No. B16041). We want to thank the support during my work at the International Joint Laboratory on Railway Engineering System Dynamics in Southwest Jiaotong University. We would like to thank $\mathrm{Xu}$ Zhang from Guangdong University of Technology, China and Shunying Ji from Dalian University of Technology, China, for their contribution to this work.

Open Access This article is licensed under a Creative Commons Attribution 4.0 International License, which permits use, sharing, adaptation, distribution and reproduction in any medium or format, as long as you give appropriate credit to the original author(s) and the source, provide a link to the Creative Commons licence, and indicate if changes were made. The images or other third party material in this article are included in the article's Creative Commons licence, unless

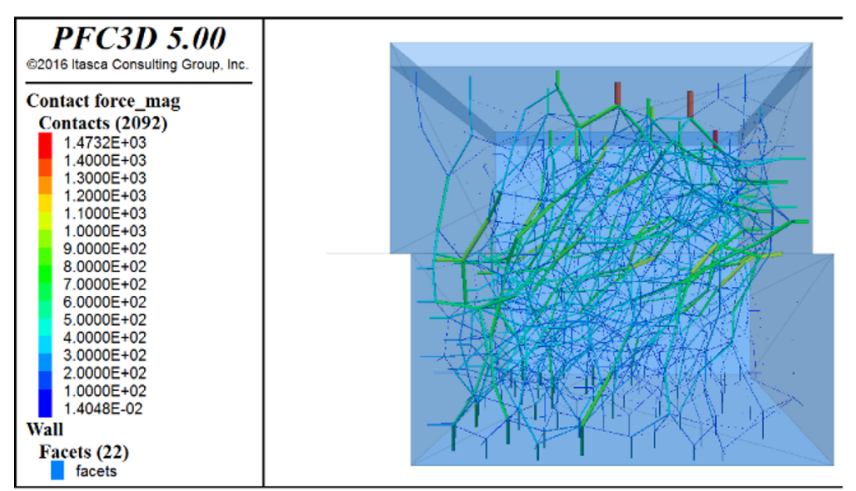

Sphere, $104 \mathrm{kPa}, 20 \mathrm{~mm}$

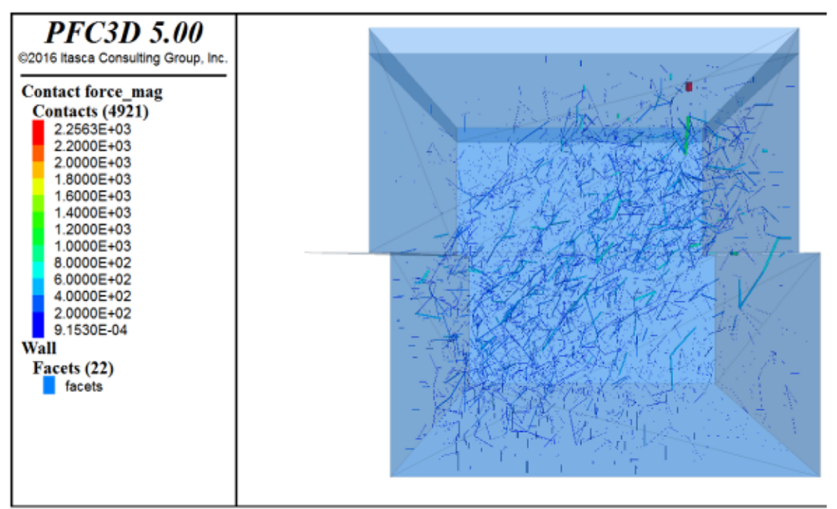

12-Sphere clump, $104 \mathrm{kPa}, 20 \mathrm{~mm}$

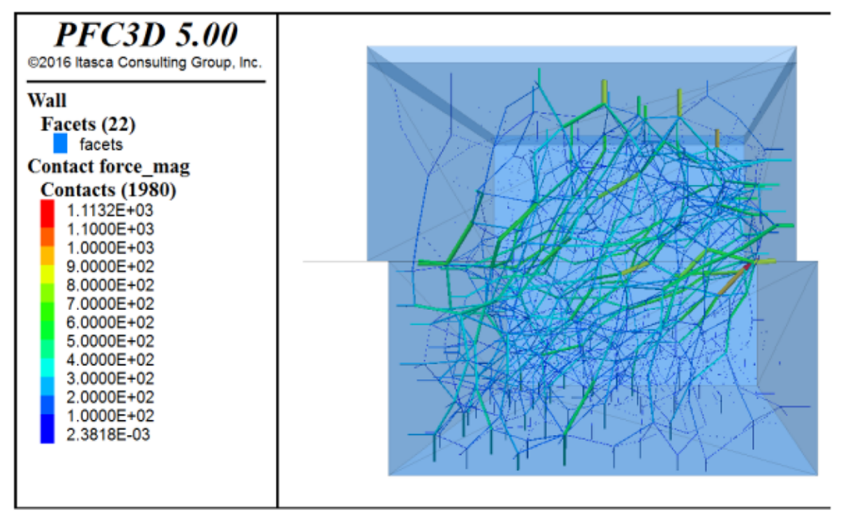

Sphere, $54 \mathrm{kPa}, 20 \mathrm{~mm}$ indicated otherwise in a credit line to the material. If material is not included in the article's Creative Commons licence and your intended use is not permitted by statutory regulation or exceeds the permitted use, you will need to obtain permission directly from the copyright holder. To view a copy of this licence, visit http://creativecommons. org/licenses/by/4.0/.

\section{Appendix}

See Figs. 14, 15, 16, and Table 3.

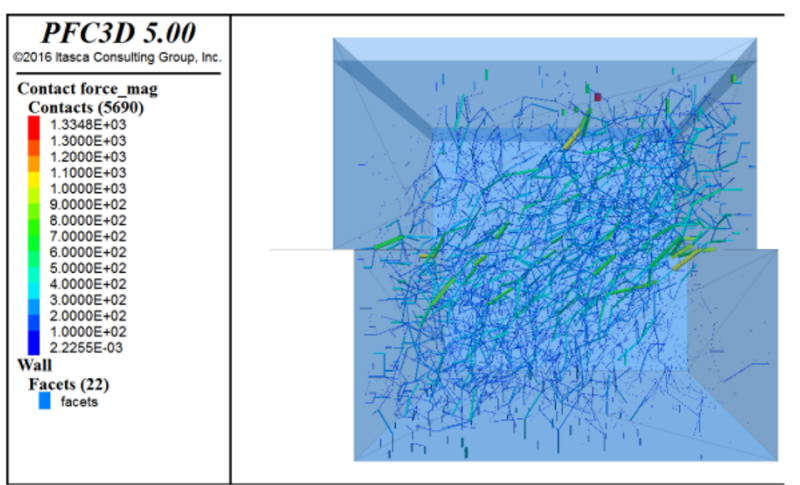

5-Sphere clump, $104 \mathrm{kPa}, 20 \mathrm{~mm}$

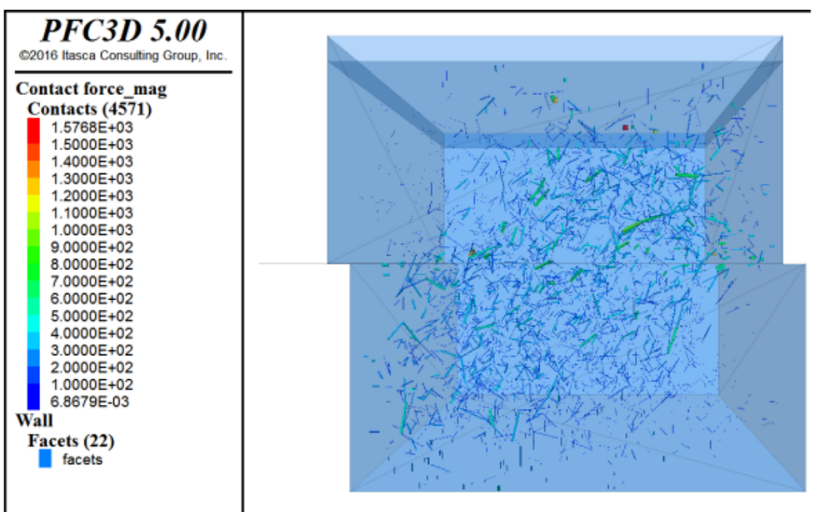

23-Sphere clump, $104 \mathrm{kPa}, 20 \mathrm{~mm}$

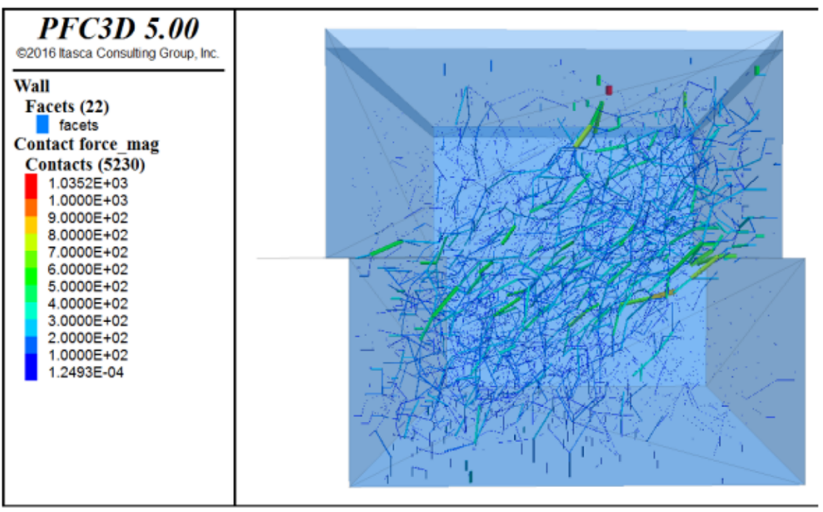

5-Sphere clump, $54 \mathrm{kPa}, 20 \mathrm{~mm}$

Fig. 14 Force chain results of the DST simulation 


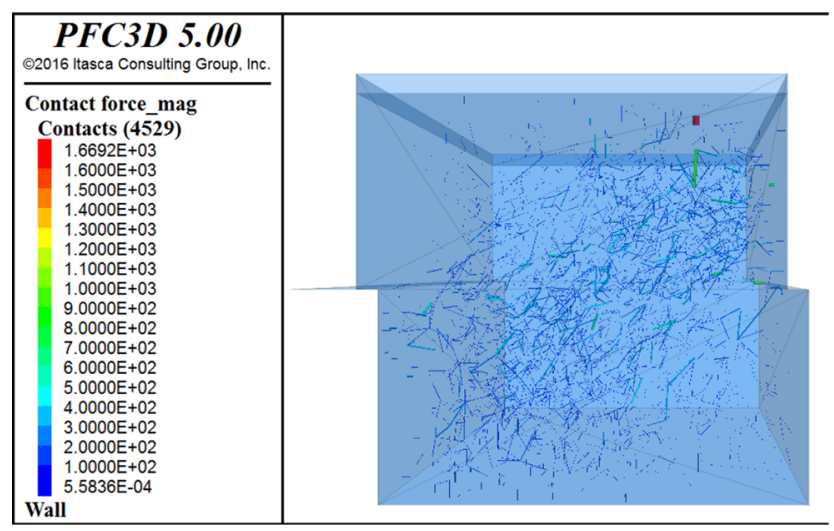

12-Sphere clump, $54 \mathrm{kPa}, 20 \mathrm{~mm}$

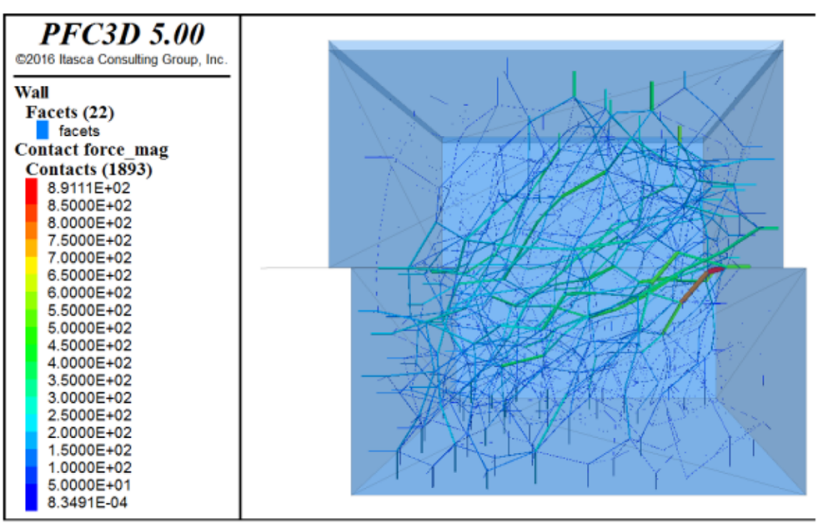

Sphere, $24 \mathrm{kPa}, 20 \mathrm{~mm}$

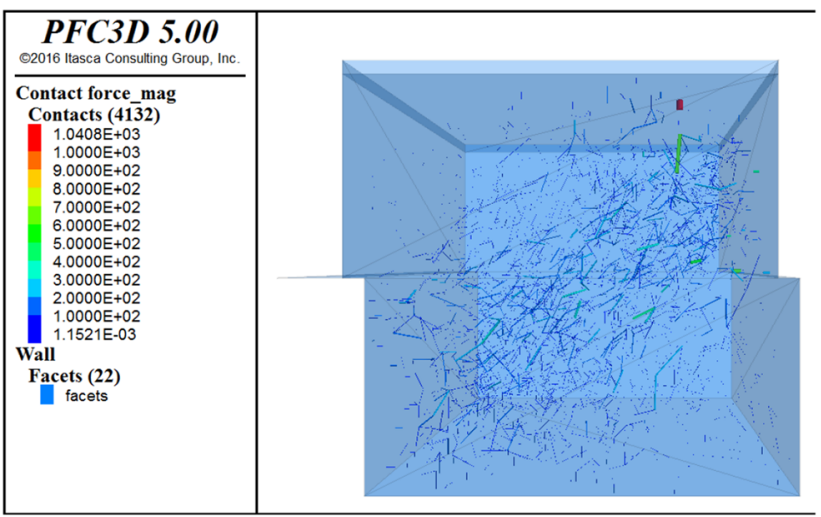

12-Sphere clump, $24 \mathrm{kPa}, 20 \mathrm{~mm}$

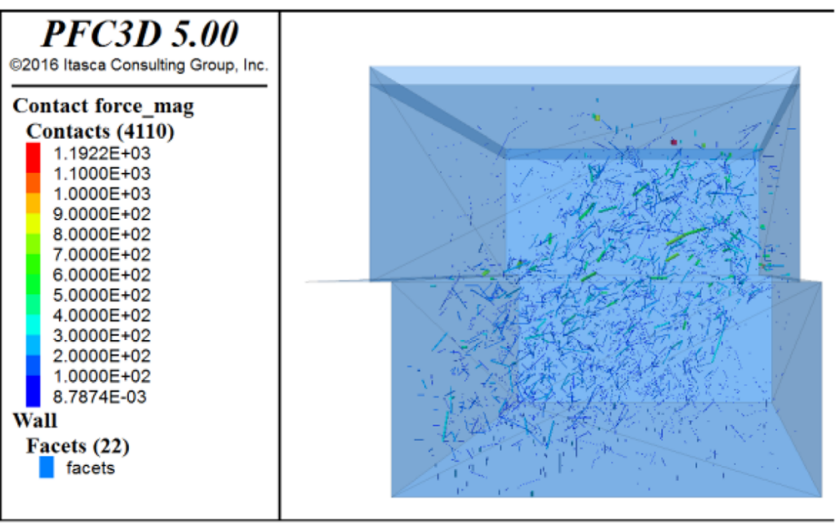

23-Sphere clump, $54 \mathrm{kPa}, 20 \mathrm{~mm}$

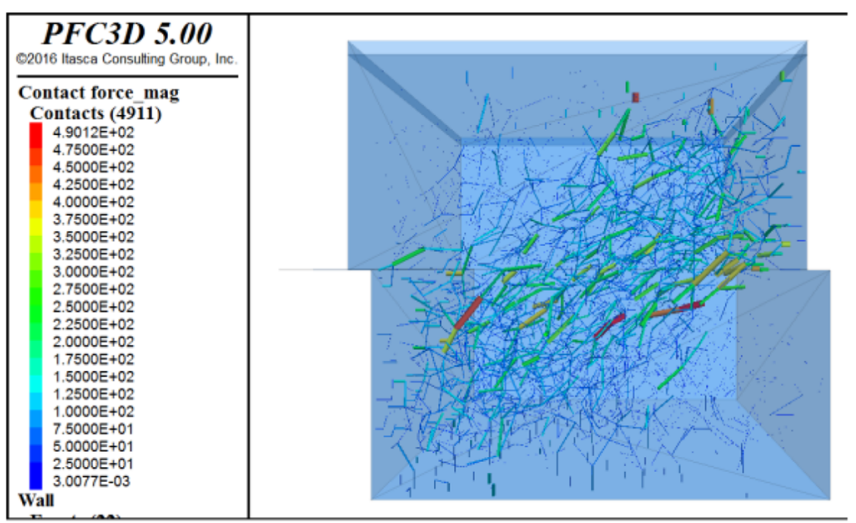

5-Sphere clump, $24 \mathrm{kPa}, 20 \mathrm{~mm}$

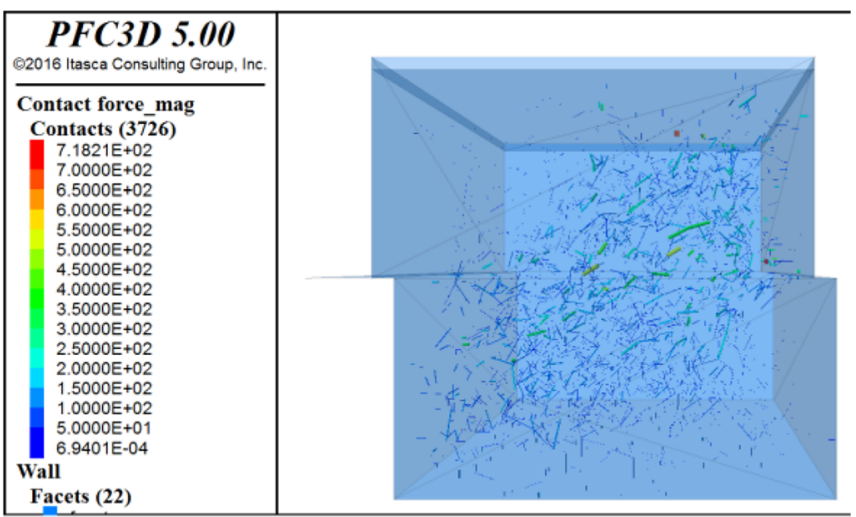

23-Sphere clump, $24 \mathrm{kPa}, 20 \mathrm{~mm}$

Fig. 14 continued 


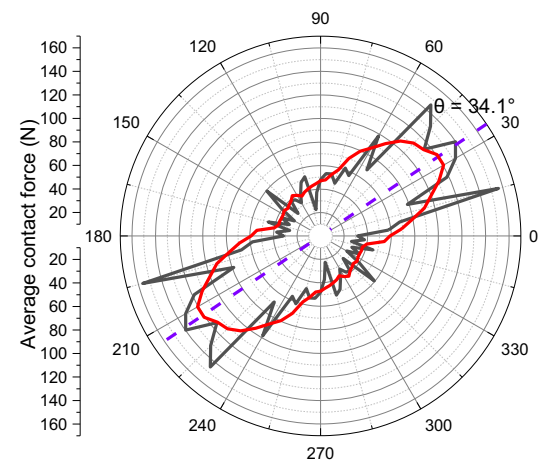

Sphere, $24 \mathrm{kPa}, 80 \mathrm{~mm}$

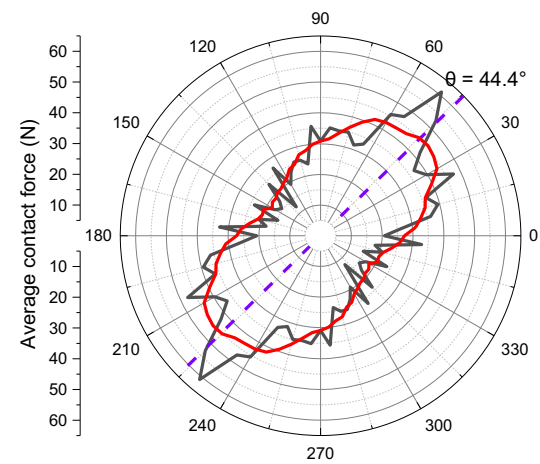

23-Sphere clump, $24 \mathrm{kPa}, 80 \mathrm{~mm}$

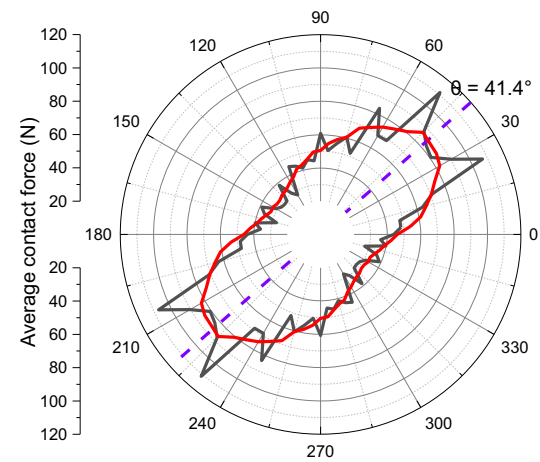

12-Sphere clump, $54 \mathrm{kPa}, 80 \mathrm{~mm}$

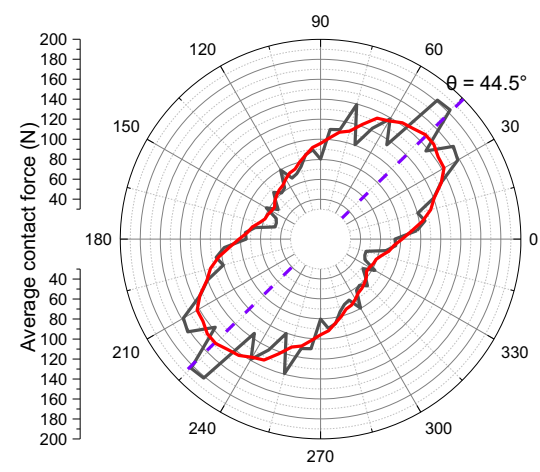

5-Sphere clump, $104 \mathrm{kPa}, 80 \mathrm{~mm}$

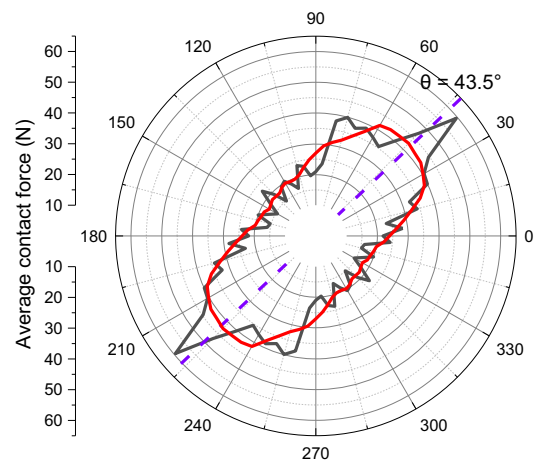

5-Sphere clump, $24 \mathrm{kPa}, 80 \mathrm{~mm}$

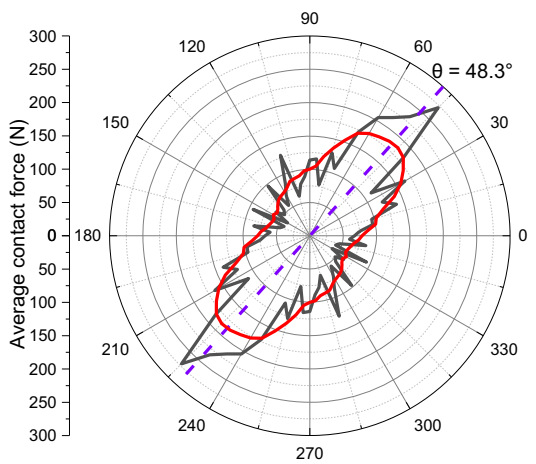

Sphere, $54 \mathrm{kPa}, 80 \mathrm{~mm}$

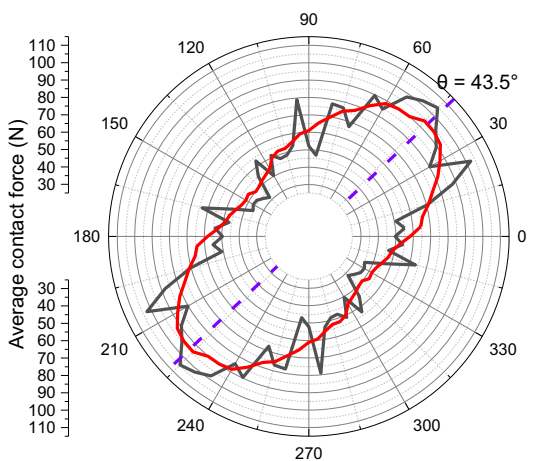

23-Sphere clump, $54 \mathrm{kPa}, 80 \mathrm{~mm}$

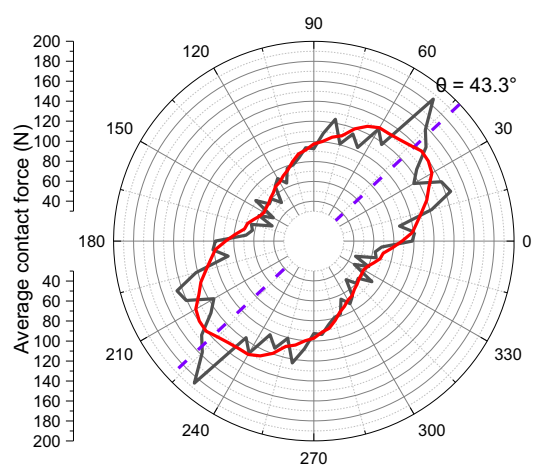

12-Sphere clump, $104 \mathrm{kPa}, 80 \mathrm{~mm}$

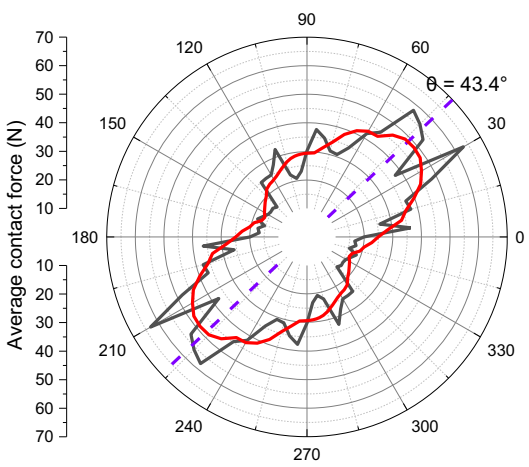

12-Sphere clump, $24 \mathrm{kPa}, 80 \mathrm{~mm}$

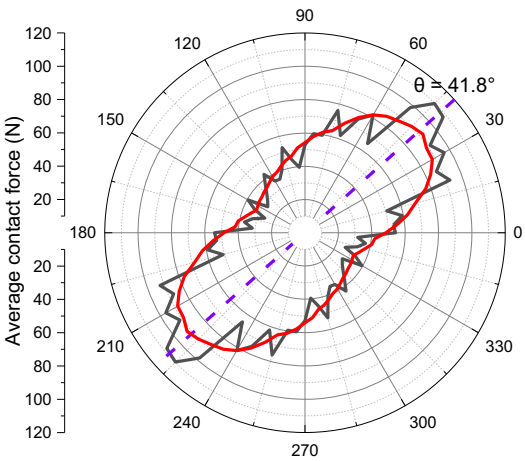

5-Sphere clump, $54 \mathrm{kPa}, 80 \mathrm{~mm}$

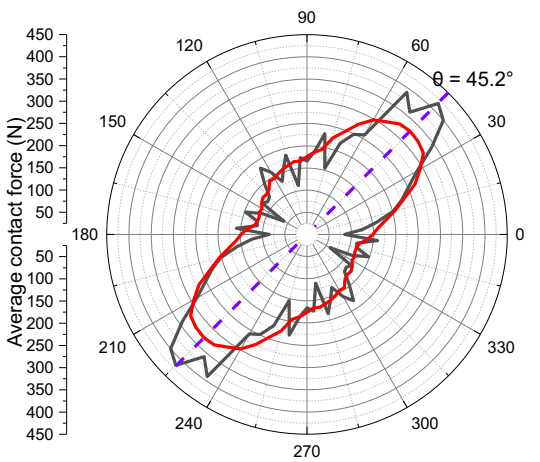

Sphere, $104 \mathrm{kPa}, 80 \mathrm{~mm}$

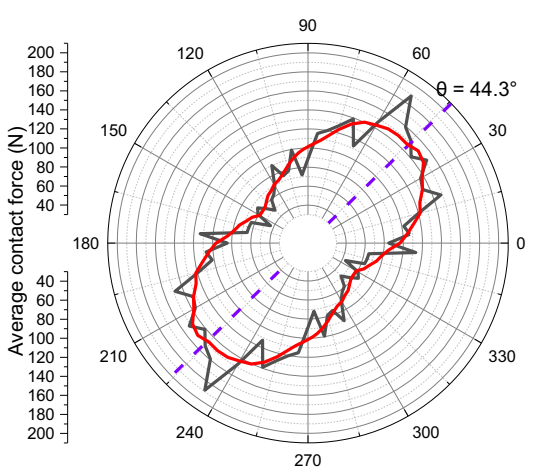

23-Sphere clump, $104 \mathrm{kPa}, 80 \mathrm{~mm}$

Fig. 15 Distributions of the particle contact forces 


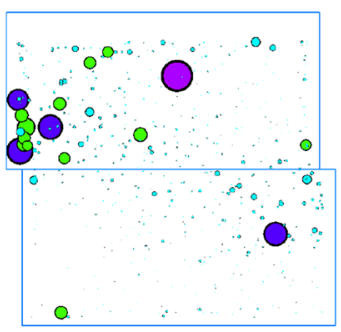

$104 \mathrm{kPa}$; sphere; displacement $20 \mathrm{~mm}$

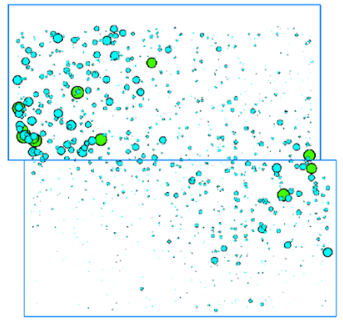

$54 \mathrm{kPa} ; 5$-sphere clump;

displacement $20 \mathrm{~mm}$

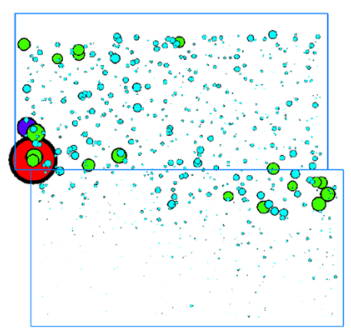

$24 \mathrm{kPa} ; 12$-sphere clump; displacement $20 \mathrm{~mm}$

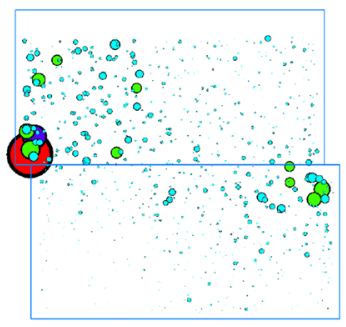

$104 \mathrm{kPa} ; 12$-sphere clump; displacement $20 \mathrm{~mm}$

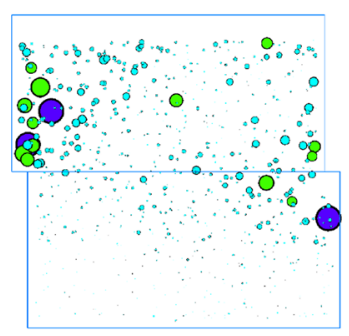

$54 \mathrm{kPa}$; 23-sphere clump; displacement $20 \mathrm{~mm}$

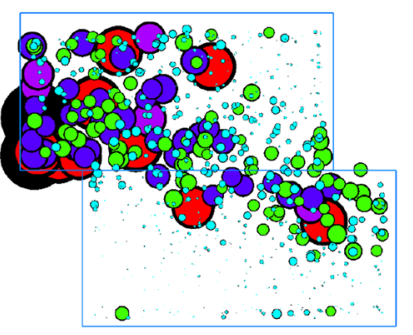

$104 \mathrm{kPa}$; sphere; displacement $80 \mathrm{~mm}$

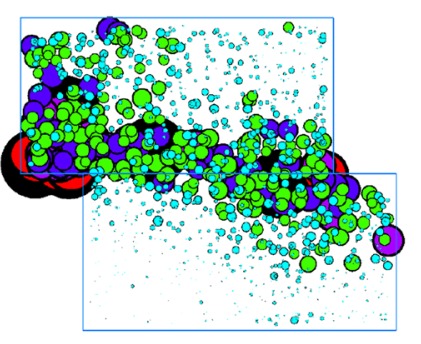

$54 \mathrm{kPa}$; 5-sphere clump;

displacement $80 \mathrm{~mm}$

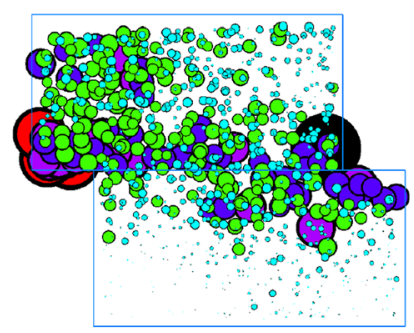

$24 \mathrm{kPa} ; 12$-sphere clump;

displacement $80 \mathrm{~mm}$

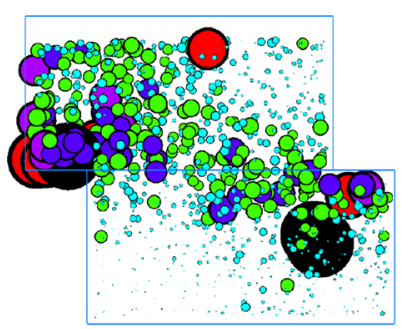

$104 \mathrm{kPa}$; 12-sphere clump; displacement $80 \mathrm{~mm}$

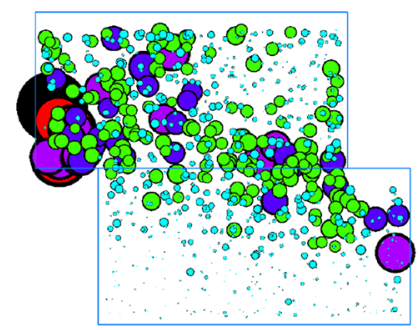

$54 \mathrm{kPa} ; 23$-sphere clump; displacement $80 \mathrm{~mm}$

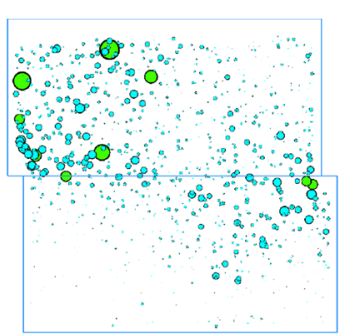

$24 \mathrm{kPa}$; 5-sphere clump;

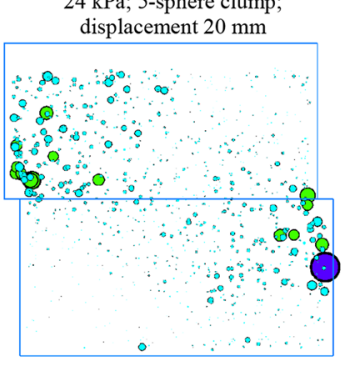

$104 \mathrm{kPa}$; 5-sphere clump; displacement $20 \mathrm{~mm}$

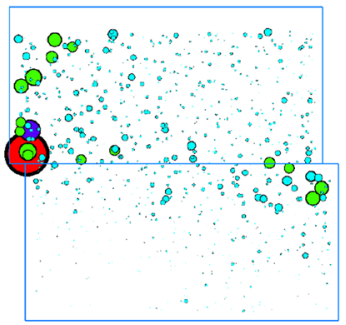

$54 \mathrm{kPa} ; 12$-sphere clump; displacement $20 \mathrm{~mm}$

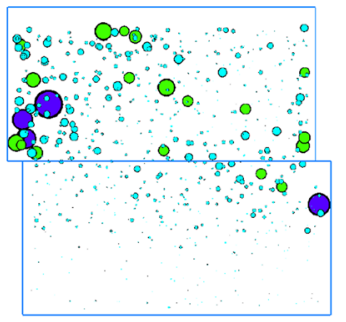

$24 \mathrm{kPa} ; 23$-sphere clump; displacement $20 \mathrm{~mm}$

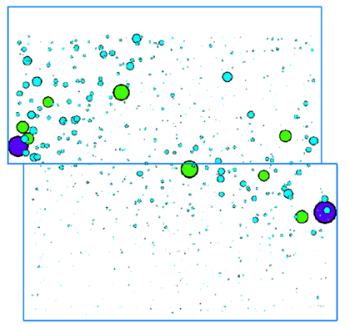

$104 \mathrm{kPa} ; 23$-sphere clump; displacement $20 \mathrm{~mm}$

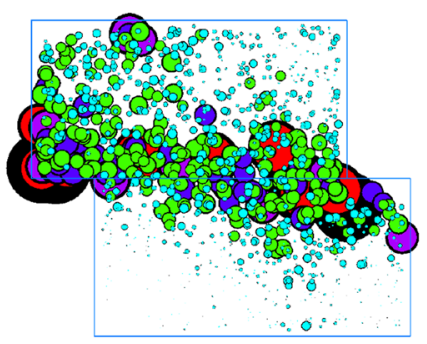

$24 \mathrm{kPa}$; 5 -sphere clump; displacement $80 \mathrm{~mm}$

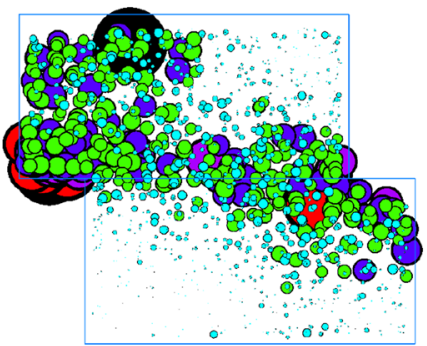

$104 \mathrm{kPa}$; 5-sphere clump; displacement $80 \mathrm{~mm}$

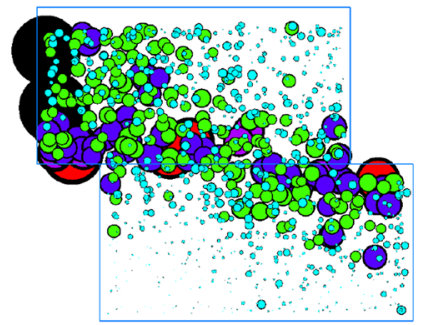

$54 \mathrm{kPa}$; 12 -sphere clump; displacement $80 \mathrm{~mm}$

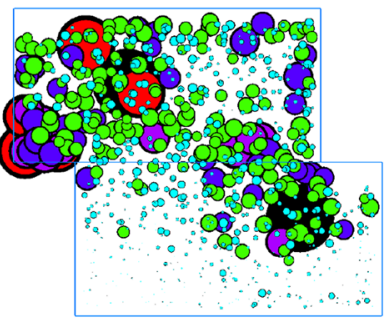

$24 \mathrm{kPa}$; 23-sphere clump; displacement $80 \mathrm{~mm}$

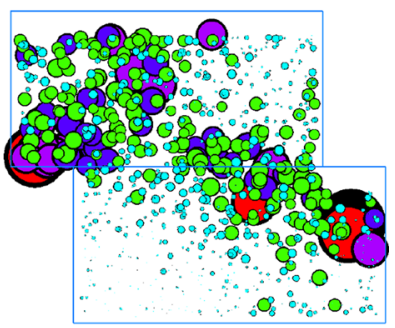

$104 \mathrm{kPa} ; 23$-sphere clump; displacement $80 \mathrm{~mm}$

Fig. 16 Particle rotation illustration of the DST models 


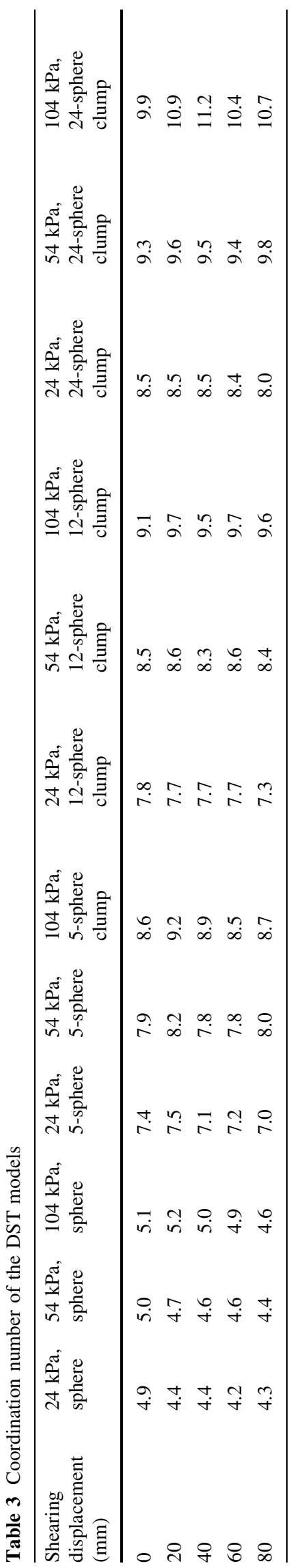

\section{References}

1. Ngo NT, Indraratna B, Rujikiatkamjorn C (2017) Stabilization of track substructure with geo-inclusions-experimental evidence and DEM simulation. Int J Rail Transp 5(2):63-86

2. Xu L, Zhai W (2020) Train-track coupled dynamics analysis: system spatial variation on geometry, physics and mechanics. Railw Eng Sci 28(1):36-53

3. Indraratna B, Ngo T (2018) Ballast railroad design: SMARTUOW approach. CRC Press, Boca Raton

4. Li D, Hyslip J, Sussmann T et al (2002) Railway geotechnics. CRC Press, Boca Raton

5. Gundavaram D, Hussaini SKK (2019) Polyurethane-based stabilization of railroad ballast: a critical review. Int J Rail Transp 7(3):219-240

6. Bakhtiary A, Zakeri JA, Mohammadzadeh S (2020) An opportunistic preventive maintenance policy for tamping scheduling of railway tracks. Int J Rail Transp. https://doi.org/10.1080/ 23248378.2020.1737256

7. BS EN 13450:2002 (2013) Aggregates for railway ballast. British Standards Institution, London

8. TB/T2140-2008 (2008) Railway Ballast. China Railway Publishing House, Beijing

9. A.R.E. Association (1995) Manual for railway engineering 1995. American Railway Engineering Association, Mitchellville

10. Zhai W, Wang K, Lin J (2004) Modelling and experiment of railway ballast vibrations. J Sound Vib 270(4):673-683

11. Ji S, Sun S, Yan Y (2015) Discrete element modeling of rock materials with dilated polyhedral elements. Procedia Eng 102:1793-1802

12. Danesh A, Palassi M, Mirghasemi AA (2018) Evaluating the influence of ballast degradation on its shear behaviour. Int J Rail Transp 6(3):145-162

13. Wang $\mathrm{P}, \mathrm{Ma} \mathrm{X}, \mathrm{Xu} \mathrm{J}$ et al (2018) Numerical investigation on effect of the relative motion of stock/switch rails on the load transfer distribution along the switch panel in high-speed railway turnout. Veh Syst Dyn 57(2):226-246

14. Li H, McDowell GR (2018) Discrete element modelling of under sleeper pads using a box test. Granul Matter 20(2):26

15. Lobo-Guerrero S, Vallejo LE (2006) Discrete element method analysis of rail track ballast degradation during cyclic loading. Granul Matter 8(3-4):195-204

16. Eliáš J (2014) Simulation of railway ballast using crushable polyhedral particles. Powder Technol 264:458-465

17. Liu S, Qiu T, Qian Y et al (2019) Simulations of large-scale triaxial shear tests on ballast aggregates using sensing mechanism and real-time (SMART) computing. Comput Geotech 110:184-198

18. Chen C, Indraratna B, McDowell G et al (2015) Discrete element modelling of lateral displacement of a granular assembly under cyclic loading. Comput Geotech 69:474-484

19. Ngo NT, Indraratna B, Rujikiatkamjorn C (2014) DEM simulation of the behaviour of geogrid stabilised ballast fouled with coal. Comput Geotech 55:224-231

20. Tutumluer E, Qian Y, Hashash YMA et al (2013) Discrete element modelling of ballasted track deformation behaviour. Int $\mathrm{J}$ Rail Transp 1(1-2):57-73

21. Jing G, Aela P, Fu H (2019) The contribution of ballast layer components to the lateral resistance of ladder sleeper track. Constr Build Mater 202:796-805

22. Xiao J, Zhang D, Wei K et al (2017) Shakedown behaviours of railway ballast under cyclic loading. Constr Build Mater $155: 1206-1214$ 
23. Zhang X, Zhao C, Zhai W (2016) Dynamic behavior analysis of high-speed railway ballast under moving vehicle loads using discrete element method. Int J Geomech 17(7):04016157

24. Lim WL, McDowell GR (2005) Discrete element modelling of railway ballast. Granul Matter 7(1):19-29

25. Deiros I, Voivret C, Combe G et al (2016) Quantifying degradation of railway ballast using numerical simulations of microdeval test and in-situ conditions. Procedia Eng 143:1016-1023

26. Zhang X, Zhao C, Zhai W (2019) Importance of load frequency in applying cyclic loads to investigate ballast deformation under high-speed train loads. Soil Dyn Earthq Eng 120:28-38

27. Jing G, Fu H, Aela P (2018) Lateral displacement of different types of steel sleepers on ballasted track. Constr Build Mater 186:1268-1275

28. Bian X, Li W, Qian Y et al (2019) Micromechanical particle interactions in railway ballast through DEM simulations of direct shear tests. Int J Geomech 19(5):04019031

29. Lu M, McDowell GR (2006) The importance of modelling ballast particle shape in the discrete element method. Granul Matter 9(1-2):69-80

30. Nishiura D, Sakai H, Aikawa A et al (2018) Novel discrete element modeling coupled with finite element method for investigating ballasted railway track dynamics. Comput Geotech 96:40-54

31. Harkness J, Zervos A, Le Pen L et al (2016) Discrete element simulation of railway ballast: modelling cell pressure effects in triaxial tests. Granul Matter 18(3):1-13

32. Ngamkhanong C, Kaewunruen S, Baniotopoulos C (2017) A review on modelling and monitoring of railway ballast. Struct Monit Maint 4(3):195-220

33. Huang H, Tutumluer E (2011) Discrete element modelling for fouled railroad ballast. Constr Build Mater 25(8):3306-3312

34. Zhang X, Zhao C, Zhai W (2017) DEM analysis of ballast breakage under train loads and its effect on mechanical behaviour of railway track. In: Proceedings of the 7th international conference on discrete element methods, vol 188, pp 1323-1333

35. Irazábal J, Salazar F, Oñate E (2017) Numerical modelling of granular materials with spherical discrete particles and the bounded rolling friction model: application to railway ballast. Comput Geotech 85:220-229

36. Huang H, Chrismer S (2013) Discrete element modeling of ballast settlement under trains moving at "critical speeds". Constr Build Mater 38:994-1000

37. Chen C, McDowell GR, Thom NH (2012) Discrete element modelling of cyclic loads of geogrid-reinforced ballast under confined and unconfined conditions. Geotext Geomembr $35: 76-86$

38. Wang Z, Jing G, Yu Q et al (2015) Analysis of ballast direct shear tests by discrete element method under different normal stress. Measurement 63:17-24

39. Itasca C, PFC (particle flow code in 2 and 3 dimensions), version 5.0 [user's manual], Minneapolis, 2014

40. Guo Y, Zhao C, Markine V et al (2020) Calibration for discrete element modelling of railway ballast: a review. Transp Geotech 23:100341

41. Zhang X (2017) Numerical simulation and experiment study on the maco-meso mechanical behaviors of high-speed railway ballast, Ph.D. thesis, Southwest Jiaotong University, Chengdu (in Chinese)

42. Indraratna B, Salim W (2003) Deformation and degradation mechanics of recycled ballast stabilised with geosynthetics. Soils Found 43(4):35-46

43. Indraratna B, Sun Q, Heitor A et al (2018) Performance of rubber tire-confined capping layer under cyclic loading for railroad conditions. J Mater Civ Eng 30(3):06017021

44. Sol-Sánchez M, Thom NH, Moreno-Navarro F et al (2015) A study into the use of crumb rubber in railway ballast. Constr Build Mater 75:19-24 